\title{
The hidden anatomy of paranasal sinuses reveals biogeographically distinct morphotypes in the nine-banded armadillo (Dasypus novemcinctus)
}

\author{
Guillaume Billet $^{\text {Corresp., }}{ }^{1}$, Lionel Hautier ${ }^{2,3}$, Benoit de Thoisy ${ }^{4,5}$, Frédéric Delsuc ${ }^{2}$ \\ 1 Sorbonne Universités, CR2P, UMR 7207, CNRS, Université Paris 06, Museum national d'Histoire naturelle, Paris, France \\ 2 Institut des Sciences de l'Evolution, UMR 5554, CNRS, IRD, EPHE, Université de Montpellier, Montpellier, France \\ 3 Mammal Section, Life Sciences, Vertebrate Division, The Natural History Museum, London, United Kingdom \\ 4 Institut Pasteur de la Guyane, Cayenne, French Guiana \\ 5 Association Kwata, Cayenne, French Guiana \\ Corresponding Author: Guillaume Billet \\ Email address: guillaume.billet@mnhn.fr
}

Background. With their Pan-American distribution, long-nosed armadillos (genus Dasypus) constitute an understudied model for Neotropical biogeography. This genus currently comprises seven recognized species, the nine-banded armadillo ( $D$. novemcinctus) having the widest distribution ranging from Northern Argentina to the South-Eastern US. With their broad diversity of habitats, nine-banded armadillos provide a useful model to explore the effects of climatic and biogeographic events on morphological diversity at a continental scale.

Methods. Based on a sample of 136 skulls of Dasypus spp. belonging to six species, including 112 specimens identified as $D$. novemcinctus, we studied the diversity and pattern of variation of paranasal cavities, which were reconstructed virtually using $\mu$ CT-scanning or observed through bone transparency.

Results. Our qualitative analyses of paranasal sinuses and recesses successfully retrieved a taxonomic differentiation between the traditional species $D$. kappleri, $D$. pilosus and $D$. novemcinctus but failed to recover diagnostic features between the disputed and morphologically similar $D$. septemcinctus and $D$. hybridus. Most interestingly, the high variation detected in our large sample of $D$. novemcinctus showed a clear geographical patterning, with the recognition of three well-separated morphotypes: one ranging from North and Central America and parts of northern South America west of the Andes, one distributed across the Amazonian Basin and central South America, and one restricted to the Guiana Shield.

Discussion. The question as to whether these paranasal morphotypes may represent previously unrecognized species is to be evaluated through a thorough revision of the Dasypus species complex integrating molecular and morphological data. Remarkably, our recognition of a distinct morphotype in the Guiana Shield area is congruent with the recent discovery of a divergent mitogenomic lineage in French Guiana. The inflation of the second medialmost pair of caudal frontal sinuses constitutes an unexpected morphological diagnostic feature for this potentially distinct species. Our results demonstrate the benefits of studying overlooked internal morphological structures in supposedly cryptic species revealed by molecular data. It also illustrates the under-exploited potential of the highly variable paranasal sinuses of armadillos for systematic studies. 


\section{The hidden anatomy of paranasal sinuses reveals biogeographically}

\section{2 distinct morphotypes in the nine-banded armadillo (Dasypus}

\section{3 novemcinctus)}

4

5 Guillaume BILLET ${ }^{1}$, Lionel HAUTIER ${ }^{2,3}$, Benoit de THOISY ${ }^{4,5}$, and Frédéric DELSUC ${ }^{2}$

7 1Sorbonne Universités, CR2P, UMR 7207, CNRS, Université Paris 06, Muséum national

8 d'Histoire naturelle, Paris, France.

9 '2Institut des Sciences de l'Evolution, UMR 5554, CNRS, IRD, EPHE, Université de Montpellier, 10 Montpellier, France.

$11{ }^{3}$ Mammal Section, Life Sciences, Vertebrate Division, The Natural History Museum, Cromwell 12 Road, London SW7 5BD, UK.

13 4Institut Pasteur de la Guyane, BP 6010, 97300 Cayenne, French Guiana.

$14{ }^{5}$ Association Kwata, BP 672, 97300 Cayenne, French Guiana.

\section{Corresponding Author}

Guillaume BILLET, guillaume.billet@mnhn.fr

\section{Abstract}

Background. With their Pan-American distribution, long-nosed armadillos (genus Dasypus) constitute an understudied model for Neotropical biogeography. This genus currently comprises seven recognized species, the nine-banded armadillo (D. novemcinctus) having the widest 
23 distribution ranging from Northern Argentina to the South-Eastern US. With their broad

24 diversity of habitats, nine-banded armadillos provide a useful model to explore the effects of

25 climatic and biogeographic events on morphological diversity at a continental scale.

26 Methods. Based on a sample of 136 skulls of Dasypus spp. belonging to six species, including

27112 specimens identified as $D$. novemcinctus, we studied the diversity and pattern of variation of

28 paranasal cavities, which were reconstructed virtually using $\mu \mathrm{CT}$-scanning or observed through

29 bone transparency.

Results. Our qualitative analyses of paranasal sinuses and recesses successfully retrieved a taxonomic differentiation between the traditional species D. kappleri, D. pilosus and D. novemcinctus but failed to recover diagnostic features between the disputed and morphologically similar D. septemcinctus and D. hybridus. Most interestingly, the high variation detected in our large sample of $D$. novemcinctus showed a clear geographical patterning, with the recognition of three well-separated morphotypes: one ranging from North and Central America and parts of northern South America west of the Andes, one distributed across the Amazonian Basin and central South America, and one restricted to the Guiana Shield.

Discussion. The question as to whether these paranasal morphotypes may represent previously unrecognized species is to be evaluated through a thorough revision of the Dasypus species complex integrating molecular and morphological data. Remarkably, our recognition of a distinct morphotype in the Guiana Shield area is congruent with the recent discovery of a divergent mitogenomic lineage in French Guiana. The inflation of the second medialmost pair of caudal frontal sinuses constitutes an unexpected morphological diagnostic feature for this potentially distinct species. Our results demonstrate the benefits of studying overlooked internal morphological structures in supposedly cryptic species revealed by molecular data. It also 
46 illustrates the under-exploited potential of the highly variable paranasal sinuses of armadillos for

47 systematic studies.

\section{Introduction}

49 Detection of cryptic diversity and pertinent delimitation of extant taxonomic entities constitute a major challenge of current-day biological research as it may have critical implications on biodiversity conservation policies (Carstens et al., 2013). Cryptic species can be defined as "two or more species that are, or have been, classified as a single nominal species because they are at least superficially morphologically indistinguishable" (Bickford et al., 2007: 149). According to this definition, the absence of diagnostic morphological characters may have impeded the recognition of species. Depending on the case, this absence might be real (i.e., populations of two cryptic species do not differ significantly in their entire anatomy) or spurious (i.e., morphological differences have been overlooked).

Advanced methods of micro computed tomography $(\mu \mathrm{CT})$ now enable an unprecedented assessment of internal anatomical structures, which can help uncover previously concealed morphological differences between taxa. The development of these non- destructive methods permits internal anatomy to be easily and systematically investigated in many taxa. These methodological improvements offer great opportunities for morphology-based phylogenetic research. In mammals, internal cranial structures certainly present a great wealth of phylogenetically informative anatomical features (e.g., Farke, 2010; Macrini, 2012; Ruf, 2014; Billet, Hautier \& Lebrun, 2015), possibly as many as the external surface of the skull. There is therefore a possibility that this large proportion of previously poorly explored morphological data contains undetected morphological differences between alleged cryptic taxa. 
The pan-American nine-banded armadillo (Dasypus novemcinctus) presents the largest

69

70

71

72

73

74

75

76

77

78

79

80

81

82

83

84

distribution of any living xenarthran species (McDonough and Loughry 2013), and constitutes an interesting model for Neotropical phylogeography. Several subspecies (five to seven) have been recognized within this species but their delineation and recognition are not consensual (Cabrera, 1958; McBee and Baker, 1982; Wetzel et al., 2008; McDonough \& Loughry 2013). In fact, most potential diagnostic characters for these subspecific distinctions are seldom detailed, often inconstant, or based on a limited number of observations (e.g., Peters, 1864; Allen, 1911; Lönnberg, 1913; Hamlett, 1939; Hooper, 1947; Russell, 1953). Taxonomy and phylogeny in long-nosed armadillos (Dasypodidae, sensu Gibb et al., 2016) particularly suffer from strong disagreement between morphological and molecular data (Castro et al., 2015; Gibb et al., 2016). Even though it was more focused on higher taxonomic levels, a recent study suggested the existence of an unrecognized species in French Guiana based on mitochondrial data (incl. mitogenomes) (Gibb et al., 2016). The Guianan entity has never been distinguished from other D. novemcinctus on a morphological basis, and might thus represent another striking case of cryptic species.

In order to explore if internal parts of the skull contain a useful phylogenetic signal, we investigated the internal paranasal sinuses and recesses (Rossie, 2006), whose complex structure has largely been ignored by morphologists working on the systematics of long-nosed armadillos (genus Dasypus). Based on $\mu \mathrm{CT}$ images of skulls, we reconstructed virtually the entire network of paranasal spaces in Dasypus species with a particular focus on specimens of D. novemcinctus covering the entire geographic range of the species. The observed patterns are described and discussed considering traditional taxonomic entities of long-nosed armadillos and in light of most recent molecular findings. A focus is made on the discriminatory power of these concealed 
91 characters in armadillos and on their utility for diagnosing taxonomic units previously regarded 92 as cryptic.

\section{Materials \& Methods}

96

97

\section{Specimens and $\mu C T$-scanning}

The total number of investigated specimens is composed of 136 skulls of Dasypus spp. harvested from various institutions worldwide (see details in Table S1), among which 112 were identified as D. novemcinctus, 1 as D. sabanicola, 13 as D. kappleri, 4 as D. hybridus, 3 as D. septemcinctus, and 3 as D. pilosus.

Among this sample, we virtually reconstructed the internal paranasal spaces in $51 \mu \mathrm{CT}$ scanned specimens belonging to D. novemcinctus $(\mathrm{n}=47)$, D. kappleri $(\mathrm{n}=1)$, D. hybridus $(\mathrm{n}=1)$, D. septemcinctus $(\mathrm{n}=1)$, and D. pilosus $(\mathrm{n}=1)$. Among the 47 D. novemcinctus specimens, 7 were considered juveniles, including a potential stillborn (NMNH 020920); the 40 remaining being adults or subadults. Age classes (juveniles vs subadults or adults) were determined based on the stages of eruption of the teeth (Ciancio, Castro \& Asher, 2012), on suture closure, and on size. The 47 D. novemcinctus specimens came from: United States $(n=3)$, Mexico $(n=4)$, Guatemala $(n=1)$, Nicaragua $(n=1)$, Costa Rica $(n=1)$, Panama $(n=1)$, Colombia $(n=6)$, Venezuela $(n=2)$, Ecuador $(n=2)$, Peru $(n=2)$, Bolivia $(n=2)$, Paraguay $(n=1)$, Guyana $(n=3)$, Suriname $(n=2)$, French Guiana ( $\mathrm{n}=3)$, Brazil $(\mathrm{n}=12$; see a list of different states in Table $\mathrm{S} 1)$, and Uruguay $(\mathrm{n}=1)$.

Digital data of all 51 specimens were acquired using X-ray micro computed tomography $(\mu \mathrm{CT})$. Most specimens were scanned on the X-ray tomography imagery platform at the Université de Montpellier (France) and on the $\mu \mathrm{CT}$-scan platform of the Imaging and Analysis Centre of the 
114 British Museum of Natural History (London, UK); one (MNHN.ZM-MO 2001.1317) was

115 scanned at the Museum National d'Histoire Naturelle (France) in Paris (AST-RX platform).

116 Detailed information about the scans and acquisition parameters can be found in Table S1.

117 Three-dimensional reconstructions and visualizations of the frontal sinuses were performed using

118 stacks of digital $\mu \mathrm{CT}$ images with AVIZO v. 6.1.1 software (Visualization Sciences Group

119 2009).

120 An additional subset of 65 D. novemcinctus, 1 D. sabanicola, 12 D. kappleri, 3 D.

121 hybridus, 2 D. septemcinctus and 2 D. pilosus specimens was added to the sample mentioned

122 above. These additional specimens correspond to:

123

i) skulls not available for $\mu \mathrm{CT}$-scanning but that allowed observing frontal sinuses boundaries through bone transparency through direct observations or photographs (NB: this was not possible for all observed skulls, some being insufficiently prepared or having no transparency of the frontal bone);

ii) $\quad \mu \mathrm{CT}$-scanned skulls whose paranasal cavities were not virtually reconstructed but their boundaries observed with ISE-Meshtools (Lebrun, 2008) with an artificial cutting of the specimen following a coronal section and with the software Landmark 3.6 (available at http://graphics.idav.ucdavis.edu/research/EvoMorph ; Institute for Data Analysis and Visualisation (C) with the option transparent

134 particularly, to include a paratype specimen of $D$. sabanicola (Mondolfi, 1968) (Table S1) (see 135 discussion for a word on the status of $D$. sabanicola). In order to identify a cavity observed with 
136 these alternative methods, we used similarities in position, shape, and topographical relationships

137 with sinuses or recesses defined in virtually reconstructed specimens.

Nomenclature of paranasal anatomy

141 To our knowledge, no detailed description of paranasal cavities exists for extant armadillos, 142 except for histological slices in Reinbach (1952a \& b). A maxillary recess is mentioned and 143 figured in Euphractus (Wible \& Gaudin, 2004) and brief notes were reported on the soft 144 paranasal anatomy in Dasypus (Soares da Silva et al., 2016). The most extensive work on 145 paranasal spaces in Cingulata concerns in fact some glyptodonts (Fernicola et al., 2012), whose 146 sinuses are very different from that of long-nosed armadillos. For these reasons, our 147 nomenclature follows several conventions used in other taxa, as detailed below. The standard 148 practice for paranasal sinuses is to name them after the bones they excavate (Novacek, 1993); we 149 respected this practice for all the cavities we detected (i.e., both sinuses and recesses). The 150 identity of the bones housing these cavities was determined through the examination of juvenile 151 specimens that display clearly visible bone sutures. Following recent works by Maier (2000), 152 Rossie (2006), and Farke (2010), we made a distinction between sinus and recess for paranasal 153 cavities. Paranasal sinuses are pneumatic and mucosa-lined spaces that are located in the bones 154 surrounding the nasal chamber (Rossie, 2006; Curtis \& Van Valkenburg, 2014). Contrary to 155 sinuses that are found between two layers of cortical bones (e.g., frontal), paranasal recesses are

156 defined as simple concavities of the nasal cavity, and are not associated with active bone removal 157 (Farke, 2010; Rossie, 2006). Hereafter, we employed the terms sinus or recess accordingly.

158 However, some cavities may apply to both definitions, with the posterior part expanding into the 
159 bone while the anterior part only represents a concavity. In order to avoid confusion in giving

160 two names to a single structure, we called sinuses the cavities that were at least partly comprised

161 between two layers of a cortical bone. Because there are often several sinuses or recesses within

162 a given bone (e.g., frontal, maxillary), we also used the English equivalents of positional terms of

163 the Nomina Anatomica Veterinaria (NAV, 2005) for the paranasal sinuses when feasible (e.g.,

164 caudal frontal sinus). It was not possible to elaborate robust homology hypotheses for all cavities

165 of the paranasal region because they are found in large numbers and may represent

166 neoformations when compared to the common terminology. Consequently, we complemented

167 the common terminology with a numbering system that allows distinguishing the numerous

168 frontal recesses and sinuses found in long-nosed armadillos. The terminology for turbinal bones,

169 which are only briefly mentioned for spatial localization of paranasal cavities, is based on Van

170 Valkenburgh, Smith \& Craven (2014) and Maier \& Ruf (2014).

171

172

Institutional abbreviations: AMNH, American Museum of Natural History, New York, USA;

173

BMNH, British Museum of Natural History (Natural History Museum), London, UK; IEPA

174 Instituto de Pesquisas Científicas e Tecnológicas do Estado do Amapá in Macapá, Brazil;

175 KWATA, Kwata Association collection, Cayenne, French Guiana; LSU, Louisiana State

176 University, Baton Rouge, LA, USA; MBUCV Museo de biología de la Universidad central de

177 Venezuela; MHNG, Muséum d'Histoire Naturelle in Geneva, Switzerland; MNHN.ZM.MO, 178 collections “Zoologie et Anatomie comparée, Mammifères et Oiseaux” of Muséum National

179 d'Histoire Naturelle, Paris, France; MUSM Museo de Historia Natural-Universidad Nacional

180 Mayor de San Marcos, Lima, Peru; NMNH, National Museum of Natural History, Smithsonian 
181 Institution; Washington, DC, USA; RMNH, Naturalis Biodiversity Center, Leiden, Netherlands

182 (Rijksmuseum van Natuurlijke Historie); ROM, the Royal Ontario Museum in Toronto, Canada.

Anatomical abbreviations and measurements: CFS, caudal frontal sinus (numbered from 0 to 5);

185

186

187

188

189

190

191

192

193

194

195

196

197

198

199

200

201

202

FR, frontal bone; LA, lacrimal bone; LTC, length total cranium, measured from the anterior nasal tip to the posteriormost extent of the nuchal occipital crests; NA, nasal bone; NSP, nasopharynx; RFR, rostral frontal recess (numbered from 1 to 3); RL, lacrimal recess (numbered from 1 to 2); RMXC, caudal maxillary recess; RMXR, rostral maxillary recess, ZA, zygomatic arch.

\section{Results}

Observations common to all long-nosed armadillos (genus Dasypus)

In all investigated long-nosed armadillos, paranasal sinuses and recesses consistently excavate the same three bones of the cranial face and vault: the lacrimal, the maxillary and the frontal. Sinuses are present only in the frontal bone of D. novemcinctus, D. pilosus, and D. kappleri; they are absent or weakly marked in D. hybridus and D. septemcinctus (Fig. 1). Only the posterior pneumatic parts of the frontal bone form sinuses whereas, more anteriorly, the pneumatization of the frontal bone forms recesses, which are in direct contact with the underlying turbinals all along their anteroposterior length. In most adult individuals of D. novemcinctus (see more details below) and D. kappleri, the frontal sinuses are almost entirely bordered by the posterior part of the fronto- and ethmoturbinals ventrally. In all species, the frontal sinuses and recesses regularly 
203 increase in height toward the front. The number of sinuses and recesses varies intragenerically

204 and these structures will be described hereafter.

205 In all Dasypus species, recesses are positioned dorsolaterally in the paranasal cavity.

206 These recesses represent large free-of-bone spaces in the nasal cavity, generally separating

207 turbinal bones medioventrally from the bones that build up the cranial walls. The lacrimal

208 recesses are in contact with the mass of fronto- and ethmoturbinals medially, whereas the

209 maxillary recesses are bordered by the naso- and maxilloturbinalsventromedially . Two distinct

210 lacrimal recesses are invariably present and are separated by the bony cover of the nasolacrimal

211 duct. Two recesses, variably individualized, excavate the maxillary bone (Fig. 1) and are

212 bordered by the nasolacrimal duct ventrolaterally. These maxillary cavities may well be

213 homologous to the maxillary sinus found in other mammals, but they are here designated as

214 recesses following the rationale specified in the Material and Methods Section.

215 In addition to the taxonomic and geographic variation described below, variable levels of

216 intra-individual asymmetry appear to affect all species and all paired paranasal spaces under

217 consideration here. This asymmetry is not directional, it is ubiquitous and present in most if not

218 all specimens, which suggests a case of fluctuating asymmetry (Van Valen, 1962). The species

219 D. kappleri seems to be characterized by stronger levels of asymmetry than the species $D$.

220 novemcinctus (see below).

221

\section{Juveniles of D. novemcinctus}

223 In addition to delivering critical information on the identity of bones housing the various sinuses

224 and recesses, the study of juvenile individuals provided some clues on the growth pattern of the

225 paranasal pneumatization in the nine-banded armadillo. Juveniles show a less tight medial 
226 contact between paired medial sinuses, such as the rostral frontal recesses (which may split in

227 RFR1 and RFR1', see below) or the caudal frontal sinuses (Fig. 2). Compared to adults, caudal

228 frontal sinuses (CFS) are less expanded posteriorly in juveniles and do not lie above the most

229 posterior part of the mass of fronto- and ethmoturbinals.

230

A very young specimen (likely a stillborn, AMNH 33150) shows that very early

231

232

233

234

235

236

237

238

239

240

241

242

243

244

245

246

247

248

ontogenetic phases of paranasal pneumatization start with a weak individualisation of the caudal

maxillary recess, whereas no other sinus or recess is individualized and the turbinals are not yet

ossified. The large cavity excavated in the posterior part of the frontals in this specimen does not represent a sinus but a transverse canal, presumably for the frontal diploic vein (Wible and

Gaudin, 2004) (Fig. 3). Other juveniles in our dataset clearly correspond to later ontogenetic stages, as indicated by their size: LTC = AMNH33150 38,93mm; LSU3244 66,14mm; NMNH 020920 72,89mm; AMNH133259 68,85mm (NB: LTC 90-105mm in adults; Hautier L., unpublished data). This age difference is confirmed by their stage of dental eruption: first decidual bicuspid tooth erupting in AMNH 33150; dP1-dP7 present in LSU3244 and NMNH 20920; dP1-dP7 and alveolus of M1 present in AMNH 133259 (see Ciancio et al., 2011). The juvenile series shows that paranasal pneumatization and turbinal ossification just barely started in perinatal stages lesser than 40\% adult skull length (AMNH 33150; Fig. 3) whereas these structures are well-developed in later stages with dp1-dp7 erupted and with $\sim 70 \%$ of adult skull length (Fig. 2).

\section{Observations common to all adults of nine-banded armadillos (D. novemcinctus)}

Skulls of adult D. novemcinctus are more pneumatized than juvenile ones (Figs. 2-4). All adult D. novemcinctus present a similar pattern of sinuses: posteriorly, a number of 5 to 6 paired CFS 
249 generally cover dorsally the posterior part of the mass of fronto- and ethmoturbinals (Figs. 1, 4

250 and 5). One medialmost and often reduced pair of CFS was identified as variably present and

251 designated as CFS 0 , in order to start numbering from 1 for the invariably present CFS. The set

252 of CFS form a continuous transversal chain of dorsal paranasal spaces between the orbits (Fig.

253 5). While the posterior part of each CFS is comprised between two layers of cortical bone, the

254 anterior part is always bordered ventrally by the fronto- and ethmoturbinals (Fig. 5). Anterior to

255 the CFS, the frontal bone houses several pairs of rostral frontal recesses (RFR). These recesses

256 show variable shapes (see below), but can be at least divided in two main areas: a medial recess

257 generally elongated (RFR1) and/or subdivided anteroposteriorly (RFR1 \& RFR1'), and a recess

258 or group of recesses that excavate the frontal bone more laterally up to the lacrimal recesses

259 (RFR2-3) (Fig. 1). Topographical criterions were used for establishing homologies and

260 numbering of the CFS, with the CFS 0-1 always located directly posterior to the RFR1 and the

261 CFS2-4 located posterior to the RFR2-3. In our sample of D. novemcinctus, the RFR1 are always

262 bordered posteriorly by one or two pairs of CFS in our sample of Dasypus novemcinctus. When

263 two pairs are present, the medialmost (or anteriormost in a few specimens; see below), CFS 0, is

264 always the smallest. Therefore, we consider that the medialmost pair is CFS1 when only one pair

265 is present (Figs. 1 and 4).

266

267 Northern morphotype of D. novemcinctus

268 Thirty nine (39) specimens from North and Central America and from the Pacific coast of

269 eastern Ecuador are attributed to this morphotype (Figs. 1, 4 and 6). Specimens attributed to this

270 group originate from (in alphabetical order of countries): Belize, Colombia (Antioquia

271 Department), Costa Rica, Ecuador (Provinces El Oro and Pichincha), Guatemala, Honduras, 
272 Mexico (Sinaloa, Tabasco, Oaxaca, Colima, Jalisco, and an undetermined locality

273 (NMNH179172) for the adults, San Luis Potosi and Morelos for the juveniles), Nicaragua, and

274 USA (states of Mississipi, Texas, Florida, Kansas, and Louisiana). The main diagnostic feature

275 for this group is the anteroposterior elongation of the CFS2 to 5; in addition, the left and right

276 CFS2 are obliquely orientated and contact each other posterior to the CFS1. Another distinctive

277 feature of this morphotype is the subdivision and the relative shortening of RFR1. As for the

278 Southern morphotype (see below), the number of CFS pairs in this group varies from 5 to 6 ,

279 because the CFS0 pair is either very reduced or absent. The CFS1 are rather small, shorter than

280 the more lateral CFSs and bordered posteriorly by the contacting pair of CFS2. The CFS2 and/or

281 CFS3 are the largest CFSs within this group, and though they do not contact posteromedially,

282 each CFS3, similarly to the CFS2, bends or orientates obliquely toward the midline posteriorly.

283 The CFS4 can be as elongated as the CFS2-3 or slightly smaller; the CFS5 are more reduced.

284 The median rostral frontal recesses are subdivided into two anteroposterior pairs RFR1 and

285 RFR1' and contrast with the long RFR1 of the Southern morphotype. The posterior pair, the

286 RFR1, apparently forms earlier within the ontogenetic sequence as it is clearly more developed

287 than RFR1' in two juvenile specimens from Mexico (Fig. 2). The shape of RFR1 in adults is

288 rather square whereas the anterior pair, RFR1', is usually slightly more elongated

289 anteroposteriorly. Lateral to the RFR1 and RFR1', the RFR2 and 3 are often well separated

290 (distinction often better marked than in the Southern group); the RFR3 is immediately lateral to

291 the RFR2. The same applies to the caudal and rostral maxillary recesses (RMXC \& RMXR),

292 which are often better separated in this morphotype compared to the Southern morphotype; the

293 caudal maxillary recess is posterolateral to the rostral one and located just anterior to the lacrimal

294 recess 2. 
because of the presence of large and posteriorly convergent CFS2 and short and subdivided

RFR1-RFR1' (Fig. 4). The other specimen from western Ecuador, BMNH 16.7.12.37, also

shows these characters through bone transparency. Nevertheless, on the virtual reconstruction of

AMNH 40984, the lateral RFR2-3 appear more subdivided than in other members of this morphotype, and also more than in other morphotypes. In addition, the anterior edge of its medialmost CFS (CFS 0) is shifted anteriorly. These unique characters could not be checked on the specimen observed on photos only.

\section{Southern morphotype of D. novemcinctus}

305

306

307

308

309

310

311

312

313

314

315

316

317

Fifty one (51) specimens (incl. the paratype of D. sabanicola) spanning the Amazon Basin (excluding the Guiana Shield) and including the southernmost distribution of the species in Uruguay show a distinct pattern of paranasal spaces (Figs. 4 and 6). Specimens attributed to this group thus span the Southern range of $D$. novemcinctus and originate from the following countries (in alphabetical order): Bolivia (states of Beni, Pando and Santa Cruz), Brazil (states of Amazonas, Para, Goias, Santa Catarina, Mato Grosso, Mato Grosso do Sul, Minas Gerais, São Paulo, Rio Grande do Sul and Espirito Santo), Colombia (Meta and Magdalena departments), Ecuador (Morona Santiago Province), Paraguay, Peru (regions of Ucayali, Ayacucho and San Martín), Uruguay, and Venezuela (states of Anzoátegui and Apure (state of the paratype of $D$. sabanicola)). The distinctive features of the Southern pattern of paranasal spaces mostly consist in an anteroposteriorly reduced posterior chain of caudal frontal sinuses and an elongated rostral frontal recess 1 (Figs. 1 and 4). In this group, the CFS0 are variably present. When present, they are generally smaller than the more lateral CFS1 to 5. The CFS1 always contact each other 
318 medially, or just at their posteromedial corner if the CFS0 are present. In most specimens, the

319 CFS are much shorter anteroposteriorly than the rostral frontal recess RFR1, usually around a 1/2

320 or $1 / 3$ ratio. Some specimens referred to this morphotype show more balanced ratios but the

321 anteroposterior length of the CFS never exceeds that of the RFR1. The CFS1 to 4 are usually of

322 similar length and width, the areas of the CFS 1 and 2 may just slightly exceed that of the others

323 in average. The lateralmost caudal frontal sinus that lies immediately medial to the orbital rim,

324 i.e. the CFS5, is generally shorter than the other CFS.

325 Additionally, many individuals of that group show a weak distinction or even a fusion

326 between the RFR2 and 3 (Figs. 1 and 4). Though the RFR2 and 3 are in average less separated

327 than in other groups of D. novemcinctus, this character is not stable within the Southern group.

328 Ontogenetic data are unfortunately lacking to state on a possible influence of development on

329 this feature. When not completely fused, the RFR 2 and 3 are often separated by a short bony 330 ridge posteriorly.

331 The maxillary recesses are located dorsal to the nasolacrimal duct and (antero)lateral to

332 the RFR1. As for the RFR2 and 3, the caudal and rostral maxillary recesses are variably distinct;

333 in average, they are less separated than in the other groups.

Guianan morphotype of D. novemcinctus

336 Seventeen (17) specimens are attributed to this group and originate from: Brazil (Amapa State),

337 French Guiana, Guyana and Suriname. The most conspicuous diagnostic feature of this group is 338 the strong inflation of the CFS2, which is by far the largest caudal frontal sinus (Figs. 1, 4, 5 and

339 6). These hypertrophied CFS2 occupy most or all the pneumatized frontal area between the 340 orbits up to the level of the anterior edge of the posterior zygomatic root posteriorly. More 
341 precisely, it is the posterior part of the CFS2 that is hypertrophied and borders all or most other

342 CFSs on their caudal side. The anterior part of the CFS2, which is sandwiched between CFS1

343 and CF3, is as narrow as the CFS3-4. The outline of CFS2 often exhibits a complex irregular

344 pattern and pairs are clearly asymmetric in all specimens (Fig. 4).

345

The CFS0 are variably present as in other groups. When present, they are rather small,

346 clearly elongated transversally and entirely bordered by the CFS1 posteriorly. In comparison to

347 other morphotypes, the CFS0 are slightly shifted anteriorly relative to other CFSs. The size and

348 shape of the CFS1 is also variable. In specimens with no CFS0, the CFS1 are much reduced and

349 rather square-shaped (AP 207; Fig. 4). In specimens with CFS0, the CFS1 are relatively larger

350 and can extend as far posteriorly as the hypertrophied CFS2. In such case (MNHN.ZM-MO

351 2001-1317), they are transversally thin and sandwiched between the pairs of CFS2 (Fig. 4). In

352 one specimen (MNHN.ZM-MO 1996-587), the CFS1 seems to be partly fused posteromedially

353 with the CFS2 on both sides. The CFS3 and 4 are considerably smaller than the CFS2, and are

354 similar in size as in the Southern morphotype. The CFS5 is generally smaller than CFS3-4, and

355 can be absent (e.g., MNHN.ZM-MO 2001-1317).

356 The configuration of the RFR1 is variable, as they seem to be irregularly divided into an

357 anterior RFR1' and posterior RFR1. The limits between these two subdivisions are not only

358 variable between individuals of this morphotype, they are also labile intra-individually: the

359 subdivisions may be marked on one side of the skull, not on the other (ROM 32275) or it may

360 follow another path (MNHN.ZM-MO 1995-553), or the boundaries may be irregularly marked

361 overall (marked on some portion, then absent, and then marked again a little farther away;

362 NMNH 339668). As in the Southern morphotype, the RFR2 and 3 are poorly distinguishable in 
363 most Guianan specimens (but this is also variable), except for a posterior demarcation that is

364 almost always present.

365 The lacrimal recesses 1 and 2 are very similar to that of the other morphotypes, also

366 delimited by the nasolacrimal duct. The intensity of the separation between the rostral and caudal

367 maxillary recesses is variable, but these recesses are otherwise very similar to other

368 morphotypes.

369

370

Problematic Specimens from Panama, Venezuela and Colombia

371 Five specimens (AMNH 32356, 37356, NMNH 281290 from Colombia, BMNH 5-7-521 from

372 Merida, Venezuela and NMNH 171052 from Panama) show somewhat intermediate

373 morphologies between the Southern and Northern morphotypes (Fig. 4). They all present CFS

374 and RFR1 of similar length and do not show a medially contacting pair of CFS2 (though close in

375 AMNH 37356). The RFR1 are usually not subdivided, except in the Venezuelan specimen and,

376 to a lesser extent, in the Colombian AMNH 32356. The CFS2 and 3 do not represent the largest

377 CFS except in the Colombian AMNH 32356 and 37356. These specimens therefore show a

378 combination of features characterizing the Southern and Northern groups.

379 In addition, the probable stillborn specimen AMNH 33150 from Colombia could not be referred 380 to any morphotype because its paranasal spaces are not fully developed yet (Fig. 3).

\section{Other Dasypus Species}

383 Greater long-nosed armadillo (D. kappleri)

384 The D. kappleri specimens present a large pneumatization of their paranasal region, as in $D$.

385 novemcinctus. However, all D. kappleri specimens exhibit less numerous, but wider and longer 
386 finger-shaped CFS than D. novemcinctus. In fact, this may be due to various partial or complete

387 fusions of the CFS with the RFR, which we tentatively identify as follows: the CFS1 and RFR1

388 are fused and occupy the medialmost region (but not posteriorly in some specimens; see below),

389 the CFS2-3 are fused with the RFR2-3 (Fig. 1). We consider that the caudal end of these

390 structures are homologous to the CFS since it is found between two layers of frontal bone. In

391 some specimens, a blunt bony bridge still marks a separation between these sinuses and recesses.

392 This general pattern is typical of the species, yet the arrangement of paranasal cavities largely

393 varies intraspecifically. Two groups can be distinguished: specimens from the Guiana Shield

394 display fused CFS1-RFR1 that reach the posterior boundary of the other CFS, whereas

395 specimens from more western locations have the right and left CFS2 that contact posteriorly in

396 the midline (Fig. S1). The relative sizes of the CFS also vary a lot, but the fused CFS2-3 with

397 RFR2-3 are in most cases the largest ones. In addition, most of these recesses show a substantial

398 amount of asymmetry, probably higher than in D. novemcinctus. Other recesses are grossly

399 similar in size and location to those described for D. novemcinctus.

400

401

Hairy long-nosed armadillo (D. pilosus)

402 The investigated specimens of $D$. pilosus probably resemble the most the $D$. novemcinctus

403 groups (Fig. 1). Conversely to D. kappleri, specimens of D. pilosus show caudal frontal sinuses

404 well-individualized from the rostral frontal recesses. However, there is some variation in the

405 shape of the caudal frontal sinuses. In the only scanned specimen of D. pilosus, the caudal frontal

406 sinuses are barely recognizable as they do not excavate the frontal bone (not found between two

407 layers of frontal bone); they are located just dorsal to the mass of fronto- and ethmoturbinals. In

408 fact, they rather represent thin cell-shaped recesses with irregular outlines, which are sandwiched 
409 between the frontal bone dorsally and the fronto- and ethmoturbinals ventrally. Conversely, the 410 two additional specimens of $D$. pilosus observed through bone transparency show slightly longer

411 caudal frontal sinuses/recesses that are better delineated. In any case, these caudal cell-shaped

412 frontal sinuses/recesses are in all three specimens comparable to the CFS of D. novemcinctus

413 groups in their number (4 to 5 pairs), dorsal outline and location. The rather short anteroposterior

414 extent and reduced mediolateral width of these CFS-like structures in D. pilosus are most

415 reminiscent of the pattern seen in the Southern group of $D$. novemcinctus. The more anterior

416 recesses resemble the RFR1 and RFR2-3 of the same Southern group, especially the

417 un(sub)divided and elongated RFR1. Remarkably, the lacrimal recesses are more elongated

418 anteroposteriorly than in other Dasypus species.

419

420

Southern long-nosed armadillo (D. hybridus) and seven banded armadillo (D. septemcinctus)

421 These two species are here described together because they exhibit strong similarities in their 422 pattern of paranasal cavities and could not be distinguished in our sample. These two small-sized

423 species show the least pneumatized skulls among our adult sample of Dasypus. Both species

424 present RFR1 that are transversely narrow and curved, never in contact medially, and thus partly

425 recall the configuration seen in young D. novemcinctus specimens (see above) (Figs. 1-2). In

426 addition, specimens of both species have poorly defined CFS, i.e., the fronto- and

427 ethmoturbinals fill in most of the space just ventral to the cranial vault made by the frontals and

428 the CFS are very thin dorsoventrally. The frontal bones are in fact poorly pneumatized and show

429 a thin diploe. Other cavities (rostral frontal recesses, lacrimal and maxillary recesses) show a

430 pattern and extent grossly similar to that of other Dasypus species.

431 


\section{Discussion}

433 Distribution and significance of paranasal pneumatization in mammals and armadillos

434 Paulli (1900a; 1900b) first provided detailed descriptions of paranasal cavities based on sagittal 435 and transverse osteological sections of mammalian skulls. With the recent development of $\mu \mathrm{CT}$ 436 and virtual modeling of internal structures, the paranasal sinuses and recesses could be more 437 systematically and precisely studied in extant mammals such as vombatiform marsupials, 438 carnivorans, artiodactyls, and primates (e.g., Rossie, 2008; Farke, 2010; Curtis \& Van 439 Valkenburg, 2014; Maier \& Ruf, 2014; Sharp, 2016). Though not yet thoroughly investigated 440 with modern techniques, these structures are also known to occur in many other groups of 441 placental mammals (Paulli, 1900a; Paulli, 1900b; Edinger, 1950; Novacek 1993) and may 442 constitute convergently lost symplesiomorphic placental features (Foster \& Shapiro, 2016).

The ubiquitous distribution of these structures in several clades of amniotes (Witmer, 1999) long raised questions regarding the potential functional role of paranasal pneumatization. As noted by Farke (2010: 988), cranial pneumatization such as paranasal sinuses "remains one of the most functionally enigmatic and debated structures within the vertebrate skull". Indeed, researchers have long speculated on the potential functional role of these air-filled chambers, and proposed a wealth of hypotheses (Blanton \& Biggs, 1969; Blaney, 1990; Marquez, 2008), most of which remain, as of today, untested. However, one of the current dominating hypotheses regards sinuses as functionless structures influenced by constraints inherent to bone growth and patterning (Witmer, 1997; Smith et al., 2005; Farke, 2010 and citations therein). In fact, sinuses

452 may just opportunistically fill space where bone is not mechanically necessary (Curtis \& Van 453 Valkenburg, 2014) and reduce skull mass in return (Curtis et al., 2015). This might be 454 compatible with the fact that the presence and extent of sinuses may, at least in some instances, 
455 be linked to size increase and to the shape of the bone in which they are contained (Weidenreich,

456 1941; Zollikofer et al., 2008; Farke, 2010; Curtis et al., 2015; Krentzel \& Angielczyk, 2016; Ito

457 \& Nishimura, 2016; Sharp \& Rich, 2016). Though these alternative architectural explanations do

458 not preclude the existence of functional advantages (e.g., to dissipate mechanical stress during

459 biting; Tanner et al., 2008), it seems that there is no overarching explanation for the function of

460 sinuses (Curtis et al., 2015).

461 A substantial variation of paranasal sinuses shape and outline has long been noted in

462 many taxa at the interspecific, intraspecific, and intra-individual levels (e.g., Paulli, 1900a;

463 Paulli, 1900b; Novacek, 1993; Farke, 2010; Curtis \& Van Valkenburg, 2014). These

464 observations clearly suggest that these structures have a non-negligible propensity to vary greatly

465 in mammals. It is questionable whether or not their high variability (sensu Hallgrímsson \& Hall,

466 2005) could make paranasal sinuses good markers of phylogenetic history. Interestingly, the

467 highly variable shape and size of the frontal sinus in modern humans proved to be largely

468 inherited from parents to children (Szilvássy, 1982) and is used in forensic science for individual

469 and population identifications (e.g., Kim et al., 2013). At higher taxonomic levels, a significant

470 phylogenetic signal was detected in the pattern of paranasal sinuses of primates and bovid

471 artiodactyls (Rossie, 2008; Farke, 2010), but the size and shape of frontal sinuses were rather

472 weakly linked with phylogenetic groupings in Carnivora (Curtis \& Van Valkenburg, 2014).

473 Similarly, the diversity of maxillary sinuses in macaques was not linked to phylogeny (Ito \&

474 Nishimura 2016) even though these structures were at least in part controlled by intrinsic genetic

475 factors (Ito et al., 2015).

476 In the case of long-nosed armadillos, the clear discrete differences in patterns of paranasal

477 sinuses observed between the different species and subgroups of Dasypus (D. novemcinctus, D. 
478 kappleri, D. pilosus, D. septemcinctus and D. hybridus) argue for a high discriminatory power

479 and a good phylogenetic signal carried by these structures within the genus. The fluctuating 480 asymmetry (Van Valen, 1962) tentatively identified for these structures in armadillos suggests 481 that they are also impacted by random perturbations of developmental processes (Klingenberg, 482 2010). Curiously, early anatomical accounts of paranasal anatomy disagreed on the presence of 483 sinuses in long-nosed armadillos. While Cuvier (1845) and Weinert (1925) correctly observed 484 the presence of such structures in long-nosed armadillos, other early authors overlooked it 485 (Paulli, 1900b; Zuckerkandl, 1887 (as cited in Weinert, 1925)). In fact, frontal sinuses were still 486 considered absent in armadillos as a whole in recent anatomical works (Novacek, 1993). Our 487 results clearly contradict these considerations and investigation of paranasal cavities in some 488 Chlamyphoridae, the sister group of Dasypodidae within Cingulata (Gibb et al., 2016), even 489 reveals homoplastic evolution of these structures in armadillos. Frontal sinus or recesses are absent in the extant chlamyphorid Euphractus sexcinctus (Wible \& Gaudin, 2004) and some «CT-scanned specimens of Cabassous unicinctus (MNHN.ZM.MO 1953-457) and Zaedyus pichiy (MNHN.ZM.MO 1917-135) do not show any free-of-bone space between the frontal and 493 the fronto- and ethmoturbinals (personal observations). On the other hand, an extensive system of paranasal sinuses exists in the extinct glyptodont Neosclerocalyptus (Fernicola et al., 2012). Further comparisons are needed in extant and fossil forms (see sinuses in the fossil D. punctatus, Castro et al., 2013), as these structures might provide potentially interesting characters for the understanding of higher-level relationships within the order (Delsuc et al., 2016). 
500 Our detailed investigation of paranasal cavities in Dasypus species revealed an important

501 variation at different levels. We briefly described the ontogenetic pattern of the paranasal sinuses

502 and recesses, which may start individualizing in perinatal stages (see also Reinbach, 1952a \& b).

503 Postnatal juvenile specimens show CFS that are less developed posteriorly when compared to

504 adult specimens, revealing the late posterior growth of these structures. Second, as indicated

505 above, adults show clear differences between traditionally recognized species, mostly in the

506 configuration of the CFS and RFR. Besides the large variation seen within D. novemcinctus (see

507 below), clear differences can be observed between D. kappleri, D. pilosus and the sister species

508 D. hybridus - D. septemcinctus. The greater long-nosed armadillo (D. kappleri) probably has the

509 most divergent morphology regarding these sinuses and recesses with the fusion of its CFS and

510 RFR. In contrast, these structures are better separated in all other long-nosed armadillos

511 reconstructed here. This is congruent with the early diverging position of D. kappleri in the

512 phylogeny of long-nosed armadillos (Gibb et al., 2016). Our sample for D. kappleri is also

513 characterized by a substantial variation, which is partly structured geographically: specimens

514 from the Guiana Shield show a CFS1-RFR1 that reaches the posterior level of other CFS,

515 whereas this is not the case in other specimens originating from more western areas in South

516 America (Fig. S1). Interestingly, these two allopatric groupings are congruent with the new

517 taxonomic subdivision proposed by Feijo \& Cordeiro-Estrela (2016), with a revised D. kappleri

518 species restricted to the Guiana Shield area, and a new species (D. pastasae) found from the

519 eastern Andes of Peru, Ecuador, Colombia, and Venezuela south of the Orinoco River into the

520 western Brazilian Amazon Basin. These preliminary results now require a larger sample,

521 including specimens referred to D. beniensis (Feijo \& Cordeiro-Estrela, 2016), in order to further

522 test species delimitation in the D. kappleri complex. 
524 similar to the Southern morphotype of $D$. novemcinctus than to any other morphotype, which

525 may have important implications on the reconstruction of its phylogenetic affinities. Castro et al.

526 (2015) found this species to be the sister group of all other species attributed to the genus

527 Dasypus, and therefore proposed to place it in its own genus Cryptophractus. This early

528 diverging position and generic status is in disagreement with a more recent mitogenomic

529 analysis, which retrieved $D$. pilosus in a more nested position within the genus Dasypus, with $D$.

530 kappleri representing the earliest diverging species (Gibb et al., 2016). Remarkably, our findings

531 may provide new morphological arguments for such a nested position of D. pilosus as

532 unambiguously supported by molecular data. The related species D. septemcinctus and $D$.

533 hybridus, for their part, closely resemble each other, as it could have been expected given their

534 overall morphological resemblance and their phylogenetic proximity. This observation adds to

535 the growing body of evidence that these two parapatric species might in fact represent a single

536 taxonomic entity with a large distribution (Abba \& Superina, 2010; Gibb et al., 2016).

537 Most importantly, the variation within the nine-banded armadillo (Dasypus

538 novemcinctus) allowed clearly separating three distinct geographical groups based on the pattern

539 of paranasal cavities (Fig. 6). These individual subsets do not exactly correspond to traditional

540 subspecies proposed for the nine-banded armadillo (McBee \& Baker, 1982) though the

541 distinction between the Northern and Central American (Northern morphotype) and the Southern

542 American (Southern morphotype) groups may recall some subspecific boundaries (see below). In

543 fact, although bone transparency often offers the possibility to observe the boundaries between

544 the frontal sinuses and recesses, it seems that these characters have long been overlooked in

545 cingulate systematics. The most interesting result lies in the distinction of a well-characterized 
546 entity restricted to the Guiana Shield area. Guianan nine-banded armadillos are distinguished by

547 an inflated CFS2 in comparison to all other armadillos investigated here. The irregular outline of

548 the CFS2 varies greatly among individuals belonging to the Guianan morphotype but its large

549 size relative to other CFS appears distinctive. While nine-banded armadillos from the Guiana

550 Shield have never been distinguished as a subspecies (i.e. they were until now considered as part

551 of the subspecies D. novemcinctus novemcintus Linnaeus 1758; Wetzel et al., 2008),

552 mitochondrial data showed that populations from French Guiana may represent an early

553 diverging and previously unrecognized lineage clearly separated from other D. novemcinctus

554 (Gibb et al., 2016). Specimens from French Guiana present unexpectedly distant mitochondrial

555 D-loop region (Huchon et al., 1999) and divergent mitogenomes (Gibb et al., 2016) from the

556 invasive US populations of nine-banded armadillos. Based on these new data, nine-banded

557 armadillos from French Guiana are supposed to have diverged 3.7 Ma ago from a clade formed

558 by other D. novemcinctus, D. sabanicola, D. mazzai and D. pilosus (Gibb et al., 2016). In this

559 regard, the new data on paranasal cavities deliver unprecedented and very enlightening results:

560 there exists a discrete morphological signal of internal cranial structures that supports the

561 distinctness not only of French Guianan specimens, but also of specimens from Suriname,

562 Guyana and the state Amapa in Brazil (Fig. 6). Based on this distribution, we refer to this entity

563 as specimens from the Guiana Shield (or Guianan specimens) whereas we do not know the exact

564 outline and boundaries of the range occupied by these distinctive armadillos. Taken together with

565 recent mitogenomic data (Gibb et al., 2016) and analyses of cranial shape variation (Hautier L.,

566 unpublished data), the paranasal autapomorphies found in this study make a strong case for the

567 distinction of nine-banded armadillo specimens from the Guiana Shield as a potentially new

568 species. The discovery of discrete paranasal characters supporting this purportedly distinct 
569 species demonstrates the necessity to study internal anatomy for a truly integrative taxonomy.

570 The number and delimitation of subspecies recognized within D. novemcinctus has long been a

571 matter of debate among armadillo taxonomists (Cabrera, 1958; McBee \& Baker, 1982; McBee,

572 1999; Wetzel et al., 2008; McDonough \& Loughry 2013). Alongside the Guianan morphotype,

573 the study of paranasal cavities also permitted to distinguish a mostly North and Central American

574 morphotype (Northern group) and another South American morphotype (Southern group), which

575 largely comes from the Amazon area (Fig. 6). The Northern morphotype is characterized by i) an

576 anteroposterior elongation of the CFS2 to 5, with the obliquely oriented pair of CFS2 contacting

577 each other posteromedially, and ii) subdivided and relatively shortened RFR1. The area where

578 this morphotype is found fully covers the proposed repartition of the subspecies D. novemcinctus

579 mexicanus (Peters, 1864), D. novemcinctus davisi Russel 1953, and part of D. novemcinctus

580 fenestratus Peters 1864, and D. novemcinctus aequatorialis Lönnberg 1913 (McBee \& Baker,

581 1982; Wetzel et al., 2008; McDonough \& Loughry, 2013). It is generally well distinguished from

582 the Southern morphotype, which is characterized by an anteroposteriorly reduced posterior chain

583 of CFS and an elongated RFR1 (Fig. 6). The area occupied by specimens belonging to this

584 morphotype corresponds mostly to the subspecies $D$. novemcinctus novemcintus (to the notable

585 exception of the Guiana Shield area) and may also cover the distribution of D. novemcinctus

586 mexianae Hagmann 1908 (Wetzel et al., 2008).

587 Problematic specimens whose pattern of paranasal sinuses is not easily referable to one of

588 the three main morphotypes are present in Panama and in the eastern parts of Colombia and

589 Venezuela (Fig. 6). This geographic area also partly corresponds to the subspecies $D$.

590 novemcinctus fenestratus (Wetzel et al., 2008). The partial incongruence of these internal data

591 with recognized subspecies of $D$. novemcinctus raises important taxonomic issues. In addition, 
592 these challenging results may also call into question the validity of the debated species Dasypus

593 sabanicola (Mondolfi, 1968; Abba \& Superina, 2010; Gibb et al., 2016), whose paratype

594 MBUCV 439 exhibits the pattern of paranasal cavities of the D. novemcinctus Southern

595 morphotype. However, this paratype represents a subadult specimen (Mondolfi, 1968), which

596 casts doubts on the growth stage exhibited by its paranasal cavities (NB: other specimens

597 attributed to this species could not be checked). The possibility also exists that this morphotype

598 represents a plesiomorphic condition within the genus, since D. pilosus also exhibits a similar

599 pattern. The question as to whether or not the three $D$. novemcinctus paranasal morphotypes

600 represent natural taxonomic entities is now to be evaluated through a thorough revision of the

601 Dasypus species complex that should integrate various morphological aspects and substantial

602 molecular data (Hautier L., unpublished data; Arteaga M-C., unpublished data). The case of the

603 problematic specimens found in Colombia, Venezuela and Panama clearly illustrates this

604 necessity.

605 The existence of different morphotypes within the large geographical range of $D$.

606 novemcinctus also raises the possibility that divergent paranasal morphologies reflect adaptation

607 to different local climatic and environmental conditions. Yet, the potential functional benefits for

608 selecting one of these paranasal patterns remain obscure. Though we cannot discard that these

609 structures have different functions and architectural constraints, genetic drift might have also

610 played an important role in the differentiation of these labile structures. Geographical and

611 environmental barriers, the Andes in particular, seem to separate some of these cranial

612 morphotypes (see also Hautier et al., unpublished data), a pattern that emphasizes the role played

613 by the Andean uplift in the diversification of several xenarthrans species (Moraes-Barros and

614 Arteaga, 2015). 


\section{Conclusions}

618 As an early worker on Dasypus systematics, Hamlett (1939: 335) noted that in spite of the 619 dispersion of $D$. novemcinctus through many geographical regions, "it remains so uniform that it 620 is apparently impossible to find external variations sufficiently constant to be of subspecific 621 rank". In fact, he suspected that cranial characters could offer the only promise for subspecific 622 analysis of the species. These words resonate particularly, as the strong geographical imprint 623 found in the variation pattern of paranasal cavities sheds new light on the delimitation of $D$. 624 novemcinctus and its subspecies. As demonstrated in this work, the investigation of frontal 625 sinuses may help to uncover previously overlooked phylogenetic subsets within the large 626 geographic range of nine-banded armadillos. This study highlights the under-exploited potential 627 of internal characters for systematic studies and their utility for detecting otherwise potentially 628 cryptic species. The strong variation and high discriminatory power found in the paranasal 629 sinuses of armadillos is even strangely reminiscent of the extremely variable frontal sinuses of 630 modern humans which can be used as forensic fingerprints (Kim et al., 2013) and kinship 631 markers (Szilvássy, 1982; Slavec, 2005). In addition to its great potential for extant species, the 632 study of the paranasal spaces also constitutes a promising approach to provide new informative 633 characters for the phylogenetic placement of fossil species of the genus Dasypus (e.g., see partly 634 exposed frontal sinuses in D. punctatus; Castro et al., 2013). 
637 We are grateful to Géraldine Véron and Aurélie Verguin (Muséum National d'Histoire Naturelle, 638 Paris), Roberto Portela Miguez, Louise Tomsett, Laura Balcells and Paula Jenkins (British 639 Museum of Natural History, London), François Catzeflis and Suzanne Jiquel (Institut des 640 Sciences de l'Evolution, Montpellier), Victor Pacheco (Dpto de Mastozoología, Museo de 641 Historia Natural, Universidad San Marcos, Lima), Eileen Westwig (American Museum of 642 Natural History, New-York), Burton Lim (Royal Ontario Museum, Toronto), Edmison Nicole 643 and Chris Helgen (National Museum of Natural History, Washington), Jake Esselstyn (Louisiana 644 State University, Bâton-Rouge), Manuel Ruedi (Muséum d'Histoire naturelle, Geneva), Claudia 645 Regina da Silva (Instituto de Pesquisas Científicas e Tecnológicas do Estado do Amapá, 646 Macapá), Steven van der Mije (Naturalis Biodiversity Center, Leiden), Lucile Dudoignon 647 (KWATA association), Maria-Clara Arteaga, Maria Nazareth da Silva (Manaus Museum) and 648 their collaborators for access to comparative material. R. Lebrun (Institut des Sciences de 649 l'Evolution, Montpellier), Farah Ahmed (British Museum of Natural History, London), Miguel 650 García-Sanz (Platform AST-RX MNHN) generously provided help and advice on the acquisition 651 of $\mu$ CT scans. Thanks to Sandrine Ladevèze for providing $\mu$ CT-scan data for Cabassous and 652 Zaedyus. Many thanks to Alana Sharp, Irina Ruf and an anonymous reviewer for their fruitful 653 comments on this manuscript. In compliance with Advantages and Benefits Sharing policy in 654 French Guiana, material from French Guiana has been registred in the collection JAGUARS 655 (http://kwata.net/la-collection-jaguars-pour-l-etude- de-la-biodiversite.html ; CITES reference: 656 FR973A) supported by Kwata NGO, Institut Pasteur de la Guyane, DEAL Guyane, and 657 Collectivité Territoriale de la Guyane. This is contribution ISEM 2017-XXX of the Institut des 658 Sciences de 1'Evolution. 


\section{References}

661 Abba AM, Superina M. 2010. The 2009/2010 armadillo Red List assessment. Edentata 11:135662184.

663

664 Allen GM. 1911. Mammals of the West Indies. Bulletin of the Museum of Comparative Zoology $665 \quad 54: 175-263$.

666

667 Bickford D, Lohman DJ, Sodhi NS, Ng PK, Meier R, Winker K, Ingram KK, Das I. 2007.

668 Cryptic species as a window on diversity and conservation. Trends in Ecology \& Evolution 22 669 (3):148-155.

670

671 Billet G, Hautier L, Lebrun R. 2015. Morphological diversity of the bony labyrinth (inner ear) in 672 extant xenarthrans and its relation to phylogeny. Journal of Mammalogy 96(4):658-672.

673

Blaney SPA. 1990. Why paranasal sinuses? Journal of Laryngology and Otology 104:690-693.

675

676 Blanton PL, Biggs NL. 1968. Eighteen hundred years of controversy: the paranasal sinuses.

677 American Journal of Anatomy 124:135-147.

678

679 Cabrera A. 1958. Catalogo de los mamíferos de América del Sur. Revista del Museo Argentino 680 de Ciencias Naturales "Bernardino Rivadavia," Buenos Aires 4:1-307. 
682 Carstens BC, Pelletier TA, Reid NM, Satler JD. 2013. How to fail at species delimitation.

683 Molecular Ecology 22(17):4369-4383.

684

685 Castro MC, Ciancio MR, Pacheco V, Salas-Gismondi RM, Bostelmann JE, Carlini AA. 2015.

686 Reassessment of the hairy long-nosed armadillo "Dasypus” pilosus (Xenarthra, Dasypodidae)

687 and revalidation of the genus Cryptophractus Fitzinger, 1856. Zootaxa 3947:30-48.

688

689 Castro MC, Ribeiro AM, Ferigolo J, Langer MC. 2013. Redescription of Dasypus punctatus

690 Lund, 1840 and considerations on the genus Propraopus Ameghino, 1881 (Xenarthra,

691 Cingulata). Journal of Vertebrate Paleontology 33(2):434-447.

692

693 Ciancio MR, Castro MC, Asher RJ. 2012. Evolutionary implications of dental eruption in 694 Dasypus (Xenarthra). Journal of Mammalian Evolution 19:1-8.

695

696 Curtis A, Van Valkenburgh B. 2014. Beyond the sniffer: frontal sinuses in Carnivora. The 697 Anatomical Record 297:2047-2064.

698

699 Curtis A, Lai G, Wei F, Van Valkenburgh B. 2015. Repeated Loss of Frontal Sinuses in Arctoid 700 Carnivorans. Journal of Morphology 276:22-32.

701

702 Cuvier G. 1845. Leçons d'anatomie comparée de Georges Cuvier, recueillies et publiées par M.

703 Duméril, 2nde édition. Tome troisième contenant le système nerveux et les organes des sens.

704 Paris : Fortin, Masson et Cie. 760 pp. 
Delsuc F, Gibb GC, Kuch M, Billet G, Hautier L, Southon J, Rouillard J-M, Fernicola JC,

707

708

709

710

711

712

713

714

715

716

717

718

719

720

721

722

723

724

725

726

727

Vizcaino SF, MacPhee RDE, Poinar HN. 2016. The phylogenetic affinities of the extinct glyptodonts. Current Biology 26:R141-R156.

Edinger T. 1950. Frontal sinus evolution (particularly in the Equidae). Bulletin of the Museum of Comparative Zoology at Harvard College 103:411-496.

Farke AA. 2010. Evolution and functional morphology of the frontal sinuses in Bovidae (Mammalia: Artiodactyla), and implications for the evolution of cranial pneumaticity. Zoological Journal of the Linnean Society 159:988-1014.

Feijo A, Cordeiro-Estrela P. 2016. Taxonomic revision of the Dasypus kappleri complex, with revalidations of Dasypus pastasae (Thomas, 1901) and Dasypus beniensis Lönnberg, 1942 (Cingulata, Dasypodidae). Zootaxa 4170(2):271-297.

Fernicola JC, Toledo N, Bargo S, Vizcaino S. 2012. A neomorphic ossification of the nasal cartilages and the structure of paranasal sinus system of the glyptodont Neosclerocalyptus Paula Couto 1957 (Mammalia, Xenarthra). Paleontologia Electronica 15(3):1-22.

Foster FR, Shapiro DF. 2016. Convergent loss of paranasal sinuses in mammals is explained by their deleterious effects on high-frequency communications. The Anatomical Record 299: 133. 
728 Gibb GC, Condamine FL, Kuch M, Enk J, Moraes-Barros N, Superina M, Poinar HN, Delsuc F.

729 2016. Shotgun mitogenomics provides a reference phylogenetic framework and timescale for

730 living xenarthrans. Molecular Biology and Evolution 33(3):621-642.

731

732 Hallgrímsson B, Hall BK. 2005. Variation and variability: central concepts in biology. In:

733 Hallgrímsson B, Hall BK, eds. Variation: A central concept in Biology. Cambridge: Elsevier

734 Academic Press, 1-7.

735

736

Hamlett GWD. 1939. Identity of Dasypus septemcinctus Linnaeus with notes on some related

737 species. Journal of Mammalogy 20:328-336.

738

739

Hooper ET. 1947. Notes on Mexican mammals. Journal of Mammalogy 28:40.

740

741 Huchon D, Delsuc F, Catzeflis FM, Douzery EJP. 1999. Armadillos exhibit less genetic

742 polymorphism in North America than in South America: nuclear and mitochondrial data confirm

743 a founder effect in Dasypus novemcinctus (Xenarthra). Molecular Ecology 8:1743-1748.

744

745 Ito T, Nishimura TD. 2016. Enigmatic diversity of the maxillary sinus in macaques and its

746 possible role as a spatial compromise in craniofacial modifications. Evolutionary Biology

$747 \quad 43: 414-426$.

748

749 Ito T, Kawamoto Y, Hamada Y, Nishimura TD. 2015. Maxillary sinus variation in hybrid

750 macaques: implications for the genetic basis of craniofacial pneumatization. Biological 
751 Journal of the Linnean Society 115(2):333-347.

752

753 Kim DI, Lee U, Park SO, Kwak DS, Han SH. 2013. Identification Using Frontal Sinus by

754 Three-Dimensional Reconstruction from Computed Tomography. Journal of Forensic Sciences

$755 \quad 58(1): 5-12$.

756

757 Klingenberg CP. 2010. Evolution and development of shape: integrating quantitative approaches.

758 Nature Reviews Genetics 11(9):623-635.

759

760 Krentzel D, Angielczyk K. 2016. Evolution, development and function of the elaborate frontal

761 sinuses in porcupines. The Anatomical Record 299:148.

762

763 Lönnberg E. 1913. Mammals from Ecuador and related forms. Arkiv för Zoologi 8:1-36.

764

765

Maier W. 2000. Ontogeny of the nasal capsule in cercopithecoids: a contribution to the

766 comparative and evolutionary morphology of catarrhines. In: Whitehead PF, Jolly CJ, eds. Old

767

World Monkeys. Cambridge: University Press, 99-132.

768

769 Maier W, Ruf I. 2014. Morphology of the nasal capsule of Primates - with special reference to 770 Daubentonia and Homo. The Anatomical Record 297:1985-2006. 
772 Macrini TE. 2012. Comparative morphology of the internal nasal skeleton of adult marsupials

773 based on X-ray computed tomography. Bulletin of the American Museum of Natural History

$774 \quad 365: 1-91$.

775

776 Marquez S. 2008. The paranasal sinuses: the last frontier in craniofacial biology. The Anatomical

777 Record 291:1350-1361.

778

779 McBee K, Baker RJ. 1982. Dasypus novemcinctus. Mammalian Species 162:1-9.

780

781 McDonough CM, Loughry WJ. 2013. The nine-banded armadillo: a natural history. Norman,

782 OK: University of Oklahoma Press, 323 pp.

783

784 Mondolfi E. 1968. Descripción de un nuevo armadillo del genero Dasypus de Venezuela

785 (Mammalia - Edentata). Memoria de la sociedad de ciencias naturales La Salle 27:149-167.

786

787 Moraes-Barros N, Arteaga MC. 2015. Genetic diversity in Xenarthra and its relevance to patterns 788 of neotropical biodiversity. Journal of Mammalogy 96(4):690-702.

790 Nomina Anatomica Veterinaria, 5th edn. 2005. Hannover, Columbia, Gent, Sapporo: Editorial

791 Committee. Available at: http://www.wava-amav.org/downloads/nav 2005.pdf. 
793 Novacek MJ. 1993. Patterns of diversity in the mammalian skull. In: Hanken J, Hall BK, eds. 794 The Skull, Volume 2: Patterns of Structural and Systematic Diversity. Chicago: University of 795 Chicago Press, pp. 438-545.

796

797 Paulli S. 1900a. Über die Pneumaticität des Schädels bei den Säugerthieren. Eine

798 morphologische Studie. II. Über die Morphologie des Siebbeins und die der Pneumaticität bei 799 den Ungulaten und Probosciden. Gegenbaurs Morphologisches Jahrbuch 28:179-251.

800

801 Paulli S. 1900b. Über die Pneumaticität des Schädels bei den Säugerthieren. Eine

802 morphologische Studie. III. Über die Morphologie des Siebbeins und die der Pneumaticität bei 803 den Insectivoren, Hyracoideen, Chiropteren, Carnivoren, Pinnipedien, Edentaten, Rodentiern, 804 Prosimiern und Primaten. Gegenbaurs Morphologisches Jahrbuch 28:483-564.

805

806 Peters W. 1864. Ueber neue Arten der Saugethier-gattungen Geomys, Haplodon und Dasypus. 807 Monatsbericht der Königlich-Preussischen Akademie der Wissenschaften zu Berlin 1865: 177808181.

809

810 Reinbach W. 1952a. Zur Entwicklung des Primordialcraniums von Dasypus novemcinctus Linné

811 (Tatusia novemcincta Lesson). Teil 1. Zeitschrift für Morphologie und Anthropologie 44: 375 812444. 
814 Reinbach W. 1952b. Zur Entwicklung des Primordialcraniums von Dasypus novemcinctus Linné

815 (Tatusia novemcincta Lesson). Teil 2. Zeitschrift für Morphologie und Anthropologie, Teil 2: Z.

816 Morph. Anthrop. 45: 1-72.

817

818 Rossie JB. 2006. Ontogeny and homology of the paranasal sinuses in Platyrrhini (Mammalia:

819 Primates). Journal of Morphology 267:1-40.

820

821 Rossie JB. 2008. The phylogenetic significance of anthropoid paranasal sinuses. The Anatomical

822 Record 291:1485-1498.

823

824 Ruf I. 2014. Comparative anatomy and systematic implications of the turbinal skeleton in

825 Lagomorpha (Mammalia). The Anatomical Record 297:2031-2046.

826

827 Russell RJ. 1953. Description of a new armadillo (Dasypus novemcinctus) from Mexico with

828 remarks on geographic variation of the species. Proceedings of the Biological Society of

829 Washington 66:21.

830

831 Sharp AC. 2016. A quantitative comparative analysis of the size of the frontoparietal sinuses and 832 brain in vombatiform marsupials. Memoirs of Museum Victoria 74:331-342.

833

834 Sharp AC, Rich TH. 2016. Cranial biomechanics, bite force and function of the endocranial

835 sinuses in Diprotodon optatum, the largest known marsupial. Journal of Anatomy 228:984-995.

836 
837 Slavec ZZ. 2005. Identification of family relationships by epigenetic traits. Anthropologischer

838 Anzeiger 63(4):401-408.

839

840 Smith TD, Rossie JB, Cooper GM, Mooney MP, Siegel MI. 2005. Secondary pneumatization of

841 the maxillary sinus in callitrichid primates: insights from immunohistochemistry and bone cell

842 distribution. The Anatomical Record Part A: Discoveries in Molecular, Cellular, and

843 Evolutionary Biology 285(2):677-89.

844

845 Soares da Silva AB, de Sousa Cavalcante MMA, Araújo JVS, de Oliveira IM, Fonseca CMB,

846 dos Santos Rizzo M, de Carvalho MAM, Júnior AMC. 2016. Anatomy of the nasal cavity of

847 nine-banded armadillo (Dasypus novemcinctus, Linnaeus, 1758). Jornal Interdisciplinar de

848 Biociências 1:1-4.

849

850 Szilvássy J. 1982. Zur Variation, Entwicklung und Vererbung der Stirnhöhlen. Annalen des

851 Naturhistorischen Museums in Wien. Serie A für Mineralogie undPetrographie, Geologie und

852 Paläontologie, Anthropologie und Prähistorie, 84:97-125.

853

854 Tanner JB, Dumont ER, Sakai ST, Lundrigan BL, Holekamp KE. 2008. Of arcs and vaults: the

855 biomechanics of bonecracking in spotted hyenas (Crocuta crocuta). Biological Journal of the

856 Linnean Society 95:246-255.

857

858 Van Valen L. 1962. A study of fluctuating asymmetry. Evolution 16(2):125-142.

859 
860 Van Valkenburgh B, Smith TD, Craven BA. 2014. Tour of a labyrinth: exploring the vertebrate

861 nose. The Anatomical Record 297:1975-1984.

862

863 Weidenreich F. 1941. The brain and its role in the phylogenetic transformation of the human 864 skull. Transactions of the American Philosophical Society 31:320-442.

865

866 Weinert H. 1925. Die Ausbildung der Stirnhohlen als stammesgeschichtliches Merkmal. Eine

867 vergleichend-anatomische Studie mit einem Atlas der Stirnhohlen und einem neuen Meftzirkel

868 zur Ermittelung der inneren Schadelmafie. Zeitschrift für Morphologie und Anthropologie 25(2):

$869243-357$.

870

871 Wetzel RM, Gardner AL, Redford KH, Eisenberg JF. 2008. Order Cingulata Illiger, 1811. In:

872 Gardner AL, ed. Mammals of South America, volume 1: marsupials, xenarthrans, shrews and 873 bats. Chicago: University of Chicago Press, pp. 128-157.

874

875 Wible JR, Gaudin TJ. 2004. On the cranial osteology of the yellow armadillo Euphractus

876 sexcinctus (Dasypodidae, Xenarthra, Placentalia). Annals of Carneggie Museum 73(3):117-196.

877

878 Witmer LM. 1997. The evolution of the antorbital cavity of archosaurs: a study in soft-tissue 879 reconstruction in the fossil record with an analysis of the function of pneumaticity. Journal of 880 Vertebrate Paleontology 17:1-73.

881 
882 Witmer LM. 1999. The Phylogenetic History of Paranasal Air Sinuses. In: Koppe T, Nagai H, 883 Alt KW, eds. The paranasal sinuses of higher primates: development, function and evolution. 884 Berlin: Quintessence, pp. 21-34.

885

886 Zollikofer CPE, Weissmann JD. 2008. A morphogenetic model of cranial pneumatization based 887 on the invasive tissue hypothesis. The Anatomical Record 291:1446-1454.

888

889

890

Zuckerkandl E. 1887. Das periphere Geruchsorgan der Säugethiere: eine vergleichend anatomische Studie. Whitefish: Kessinger Publishing, 146pp.

891

892

893

894 Figure legends

895 Figure 1. Dorsal views of virtually reconstructed skulls of long-nosed armadillos species, with 896 bone transparency showing internal paranasal sinuses and recesses in light blue. A-C, D.

897 novemcinctus; D, D. pilosus; E, D. hybridus; F, D. septemcinctus; G, D. kappleri. See Material 898 and Methods for the abbreviations. Scale-bar: $10 \mathrm{~mm}$.

899

900 Figure 2. Paranasal sinuses and recesses in juvenile individuals of Dasypus novemcinctus, 901 virtual reconstructions of skulls in lateral (A, C, E) and dorsal views (B, D, F), with and without 902 bone transparency. See Material and Methods for the abbreviations. Scale-bar: 10mm. 903 
904 Figure 3. Virtual reconstruction of the skull of the stillborn specimen AMNH 33150, Dasypus

905 novemcinctus, with bone transparency leaving the caudal maxillary recess and cavity for the

906 frontal diploic vein apparent. A, dorsal view; B, lateral view.

907

908 Figure 4. Dorsal views of virtually reconstructed skulls of adult specimens of Dasypus

909 novemcinctus clustered by morphotypes of paranasal anatomy as described in the text. A-F,

910 northern morphotype; G-L, southern morphotype; M-P, Guianan morphotype; Q-R, problematic

911 specimens (see text). Bone transparency leaves apparent the paranasal recesses and sinuses in

912 light blue. Scale bar: $10 \mathrm{~mm}$.

913

914 Figure 5. $\mu \mathrm{CT}$ transversal slices through the skull of $D$. novemcinctus individuals showing

915 details of the internal paranasal anatomy for each morphotype (A, northern; B, southern; C,

916 Guianan). Slices were made at similar transversal locations at the posterior end of the anterior

917 root of the zygomatic arch. See Material and Methods for the abbreviations. Scale-bar: 10mm.

918

919 Figure 6. Summary map showing the geographical distribution of nine-banded armadillo

920 specimens (Dasypus novemcinctus) investigated in this study and their attribution to a paranasal

921 morphotype. Each morphotype is represented by a schematic dorsal view of skulls (in grey) on

922 which the paranasal sinuses and recesses are drawn (in blue, yellow, or green for each

923 morphotype). Specimens reported with a star denote the absence of geographical information

924 besides the country of origin.

925

926 


\section{Figure 1}

Figure 1. Dorsal views of virtually reconstructed Dasypus skulls with internal paranasal sinuses

Dorsal views of virtually reconstructed skulls of long-nosed armadillos species, with bone transparency showing internal paranasal sinuses and recesses in light blue. A-C, D.

novemcinctus; D, D. pilosus; E, D. hybridus; F, D. septemcinctus; G, D. kappleri. See Material and Methods for the abbreviations. Scale-bar: $10 \mathrm{~mm}$. 


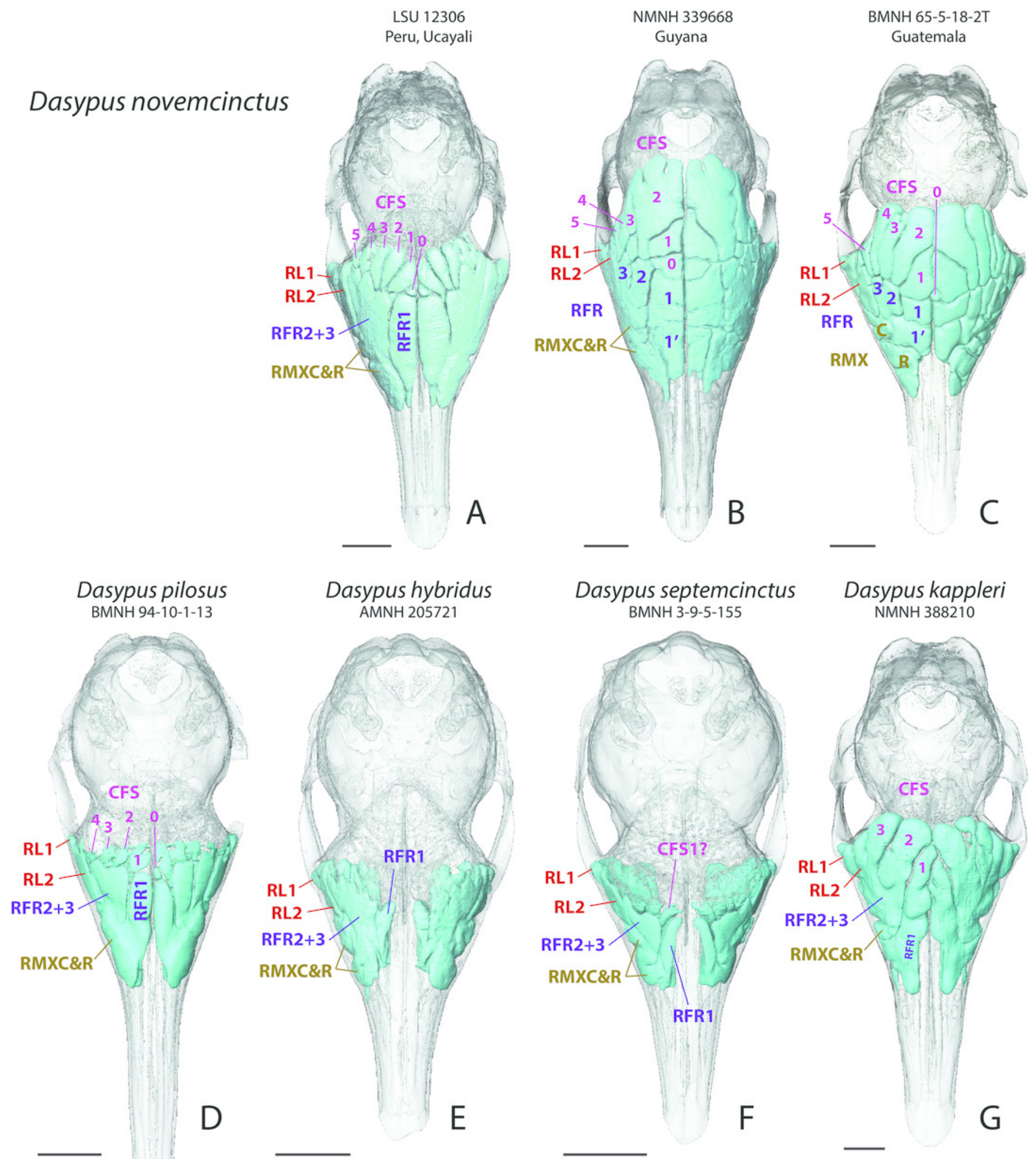


Figure 2

Figure 2. Paranasal sinuses and recesses in juvenile individuals of Dasypus novemcinctus

Paranasal sinuses and recesses in juvenile individuals of Dasypus novemcinctus, virtual reconstructions of skulls in lateral $(A, C, E)$ and dorsal views $(B, D, F)$, with and without bone transparency. See Material and Methods for the abbreviations. Scale-bar: $10 \mathrm{~mm}$. 

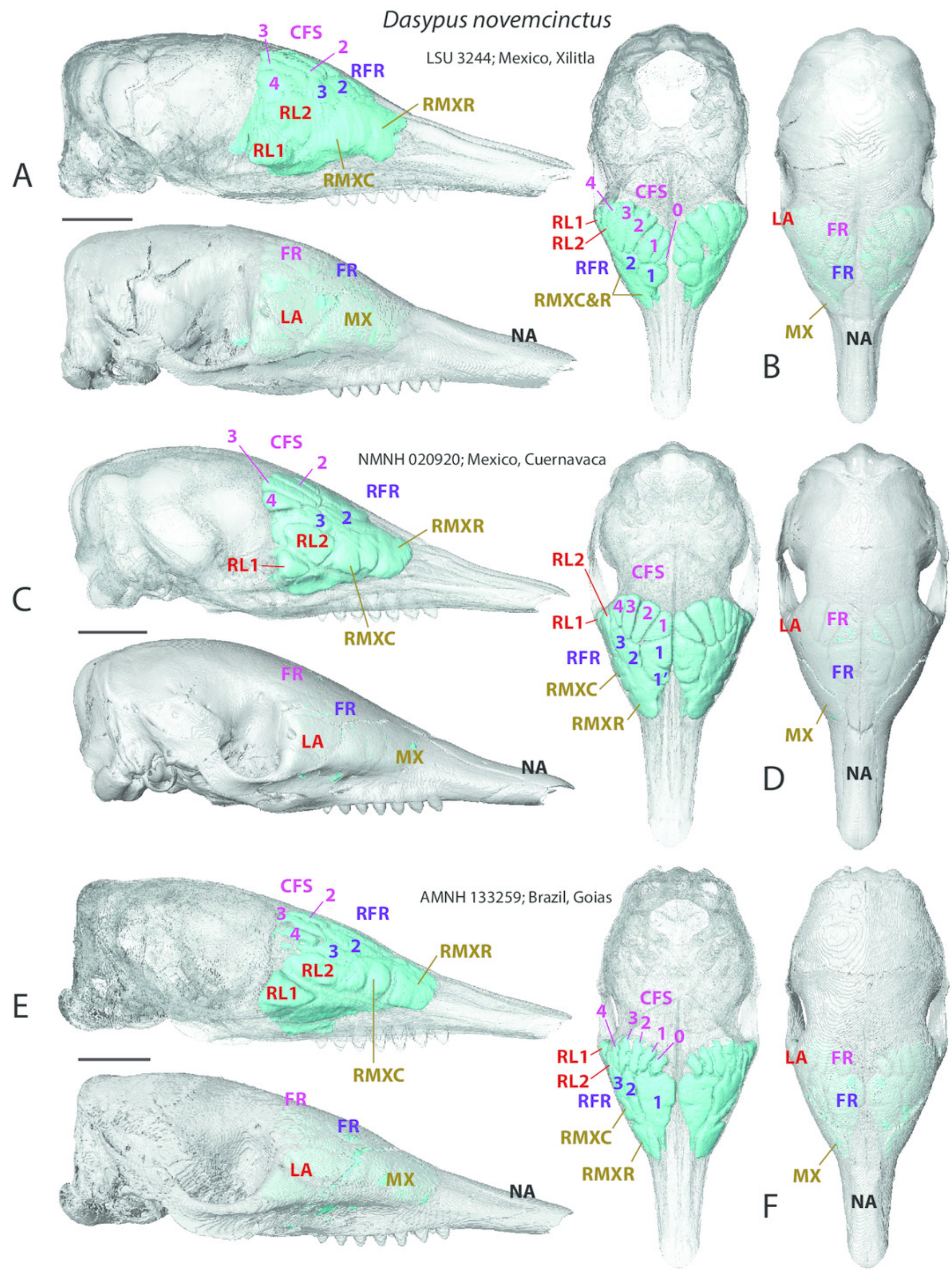


\section{Figure 3}

Figure 3. Virtual reconstruction of the skull of the stillborn specimen AMNH 33150, Dasypus novemcinctus

Virtual reconstruction of the skull of the stillborn specimen AMNH 33150, Dasypus

novemcinctus, with bone transparency leaving the caudal maxillary recess and cavity for the frontal diploic vein apparent. A, dorsal view; B, lateral view. 


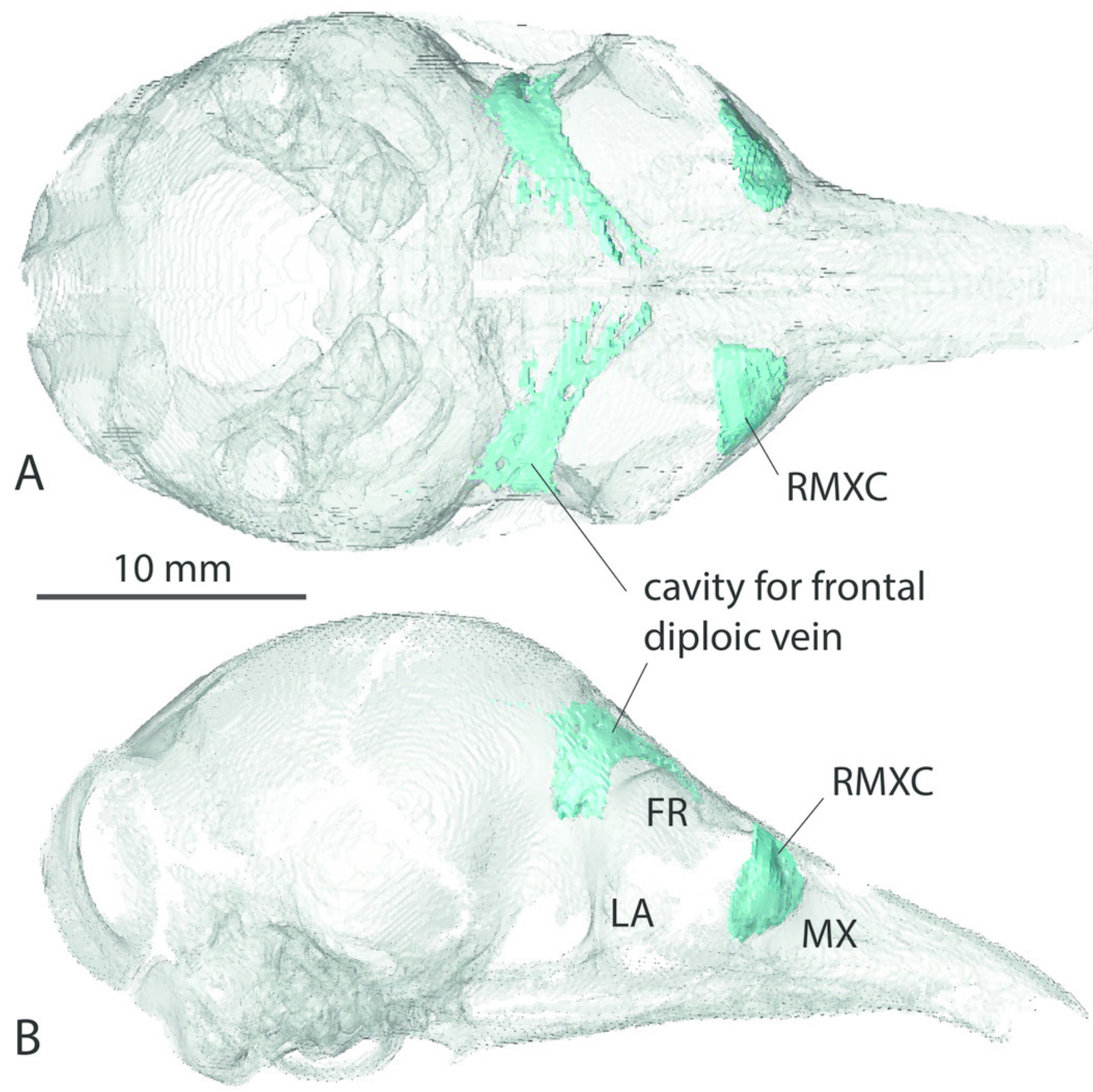




\section{Figure 4}

Figure 4. Dorsal views of virtually reconstructed skulls of adult specimens of Dasypus novemcinctus clustered by morphotypes of paranasal anatomy as described in the text.

A-F, northern morphotype; G-L, southern morphotype; M-P, Guianan morphotype; Q-R, problematic specimens (see text). Bone transparency leaves apparent the paranasal recesses and sinuses in light blue. Scale bar: $10 \mathrm{~mm}$. 

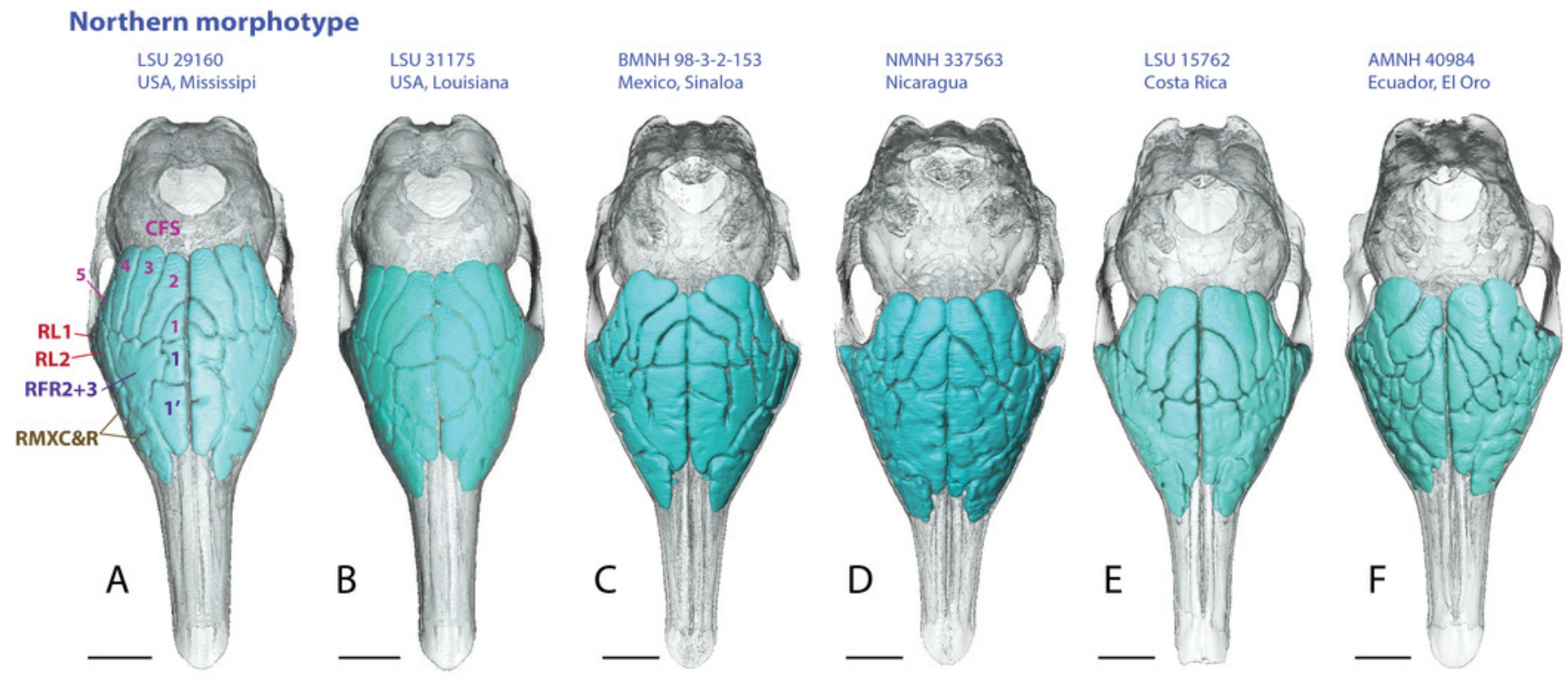

\section{Southern morphotype}
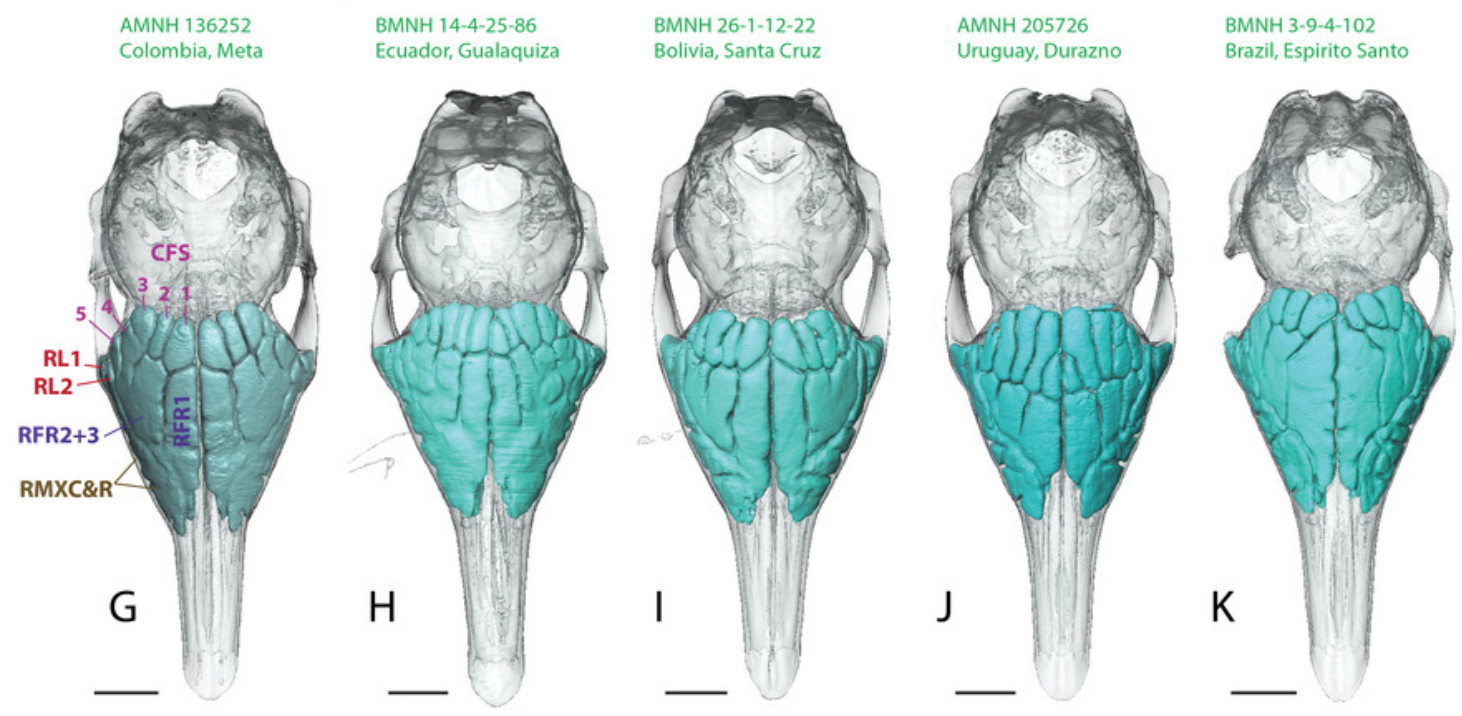

AMNH 133338

Brazil, Para

Guianan morphotype
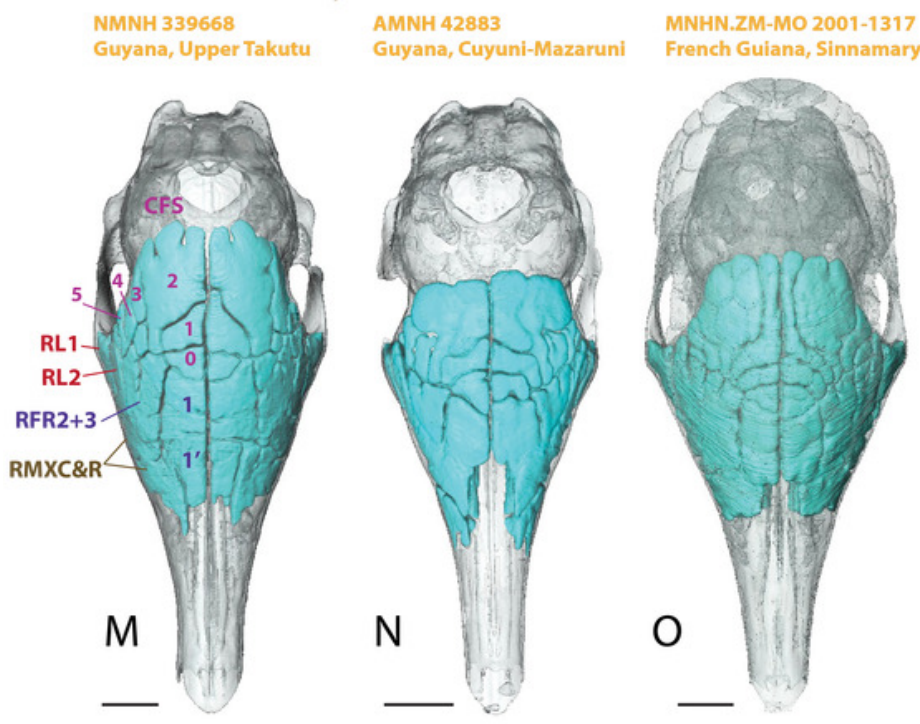

AP 207

Brazil, Amapa

Problematic specimens

NMNH 171052

BMNH 5-7-5-21
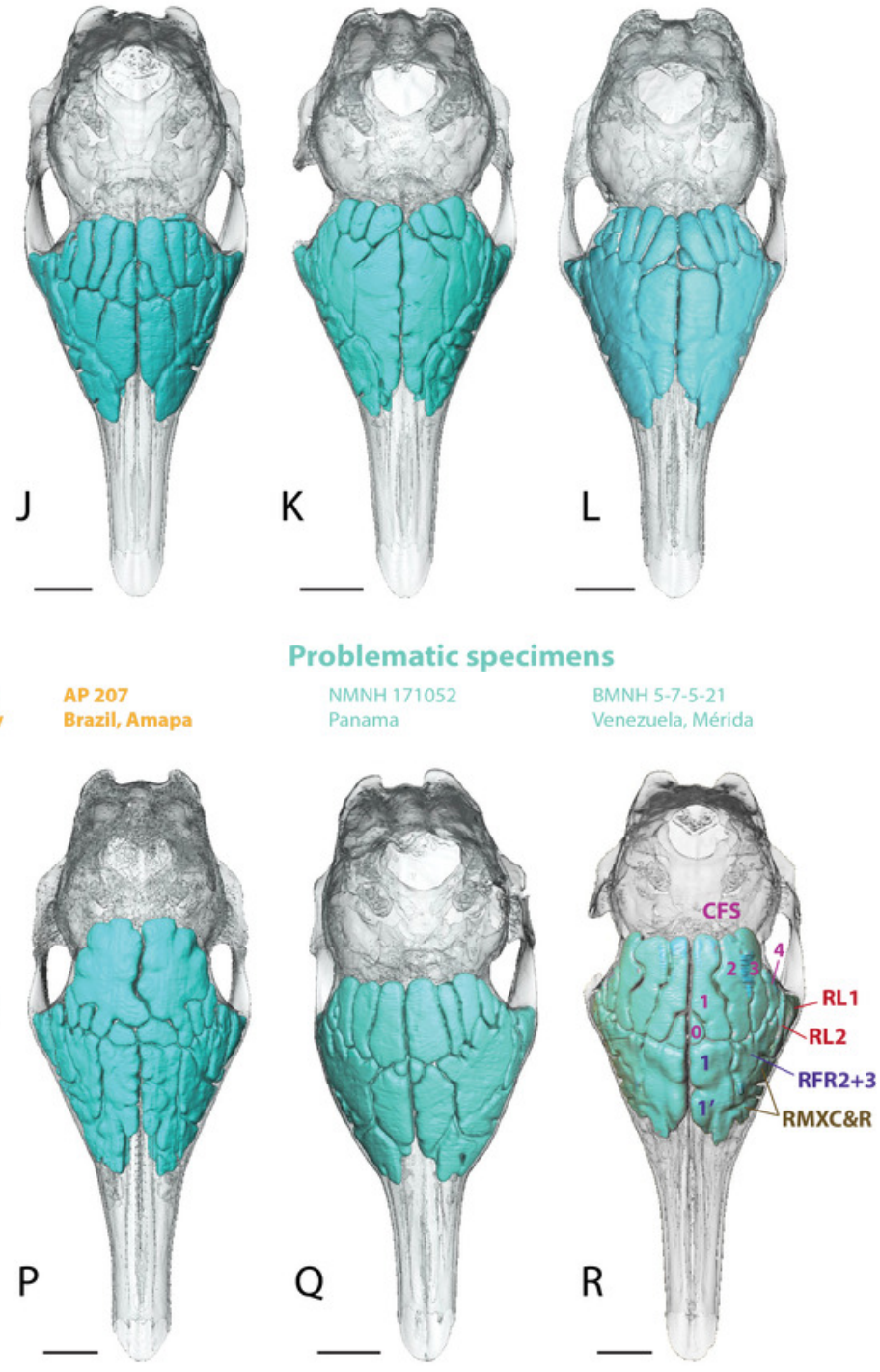

Venezuela, Mérida 


\section{Figure 5}

Figure 5. $\mu \mathrm{CT}$ transversal slices through the skull of $D$. novemcinctus individuals showing details of the internal paranasal anatomy for each morphotype (A, northern; $B$, southern; C, Guianan).

Slices were made at similar transversal locations at the posterior end of the anterior root of the zygomatic arch. See Material and Methods for the abbreviations. Scale-bar: 10mm.

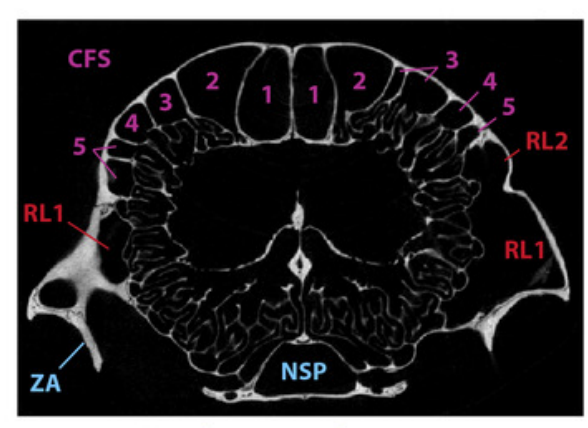

A

Northern morphotype LSU 15762

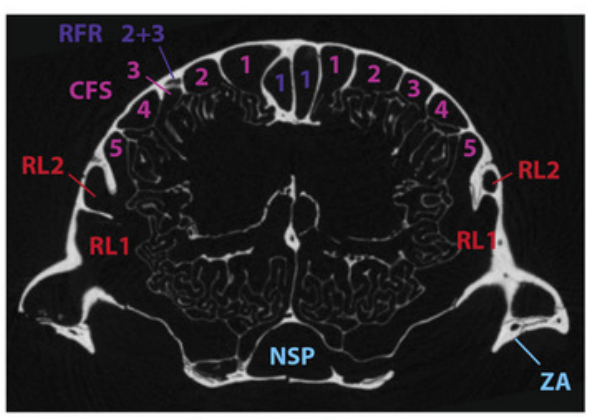

Southern morphotype BMNH 3-9-4-102

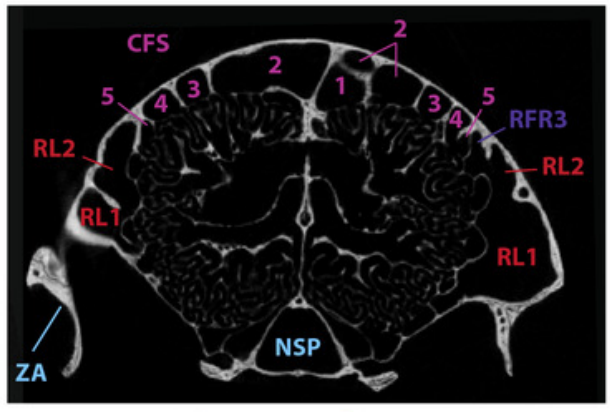

Guianan morphotype AP 207 


\section{Figure 6}

Figure 6. Summary map showing the geographical distribution of nine-banded armadillo specimens (Dasypus novemcinctus) investigated in this study and their attribution to a paranasal morphotype.

Each morphotype is represented by a schematic dorsal view of skulls (in grey) on which the paranasal sinuses and recesses are drawn (in blue, yellow, or green for each morphotype). Specimens reported with a star denote the absence of geographical information besides the country of origin. 


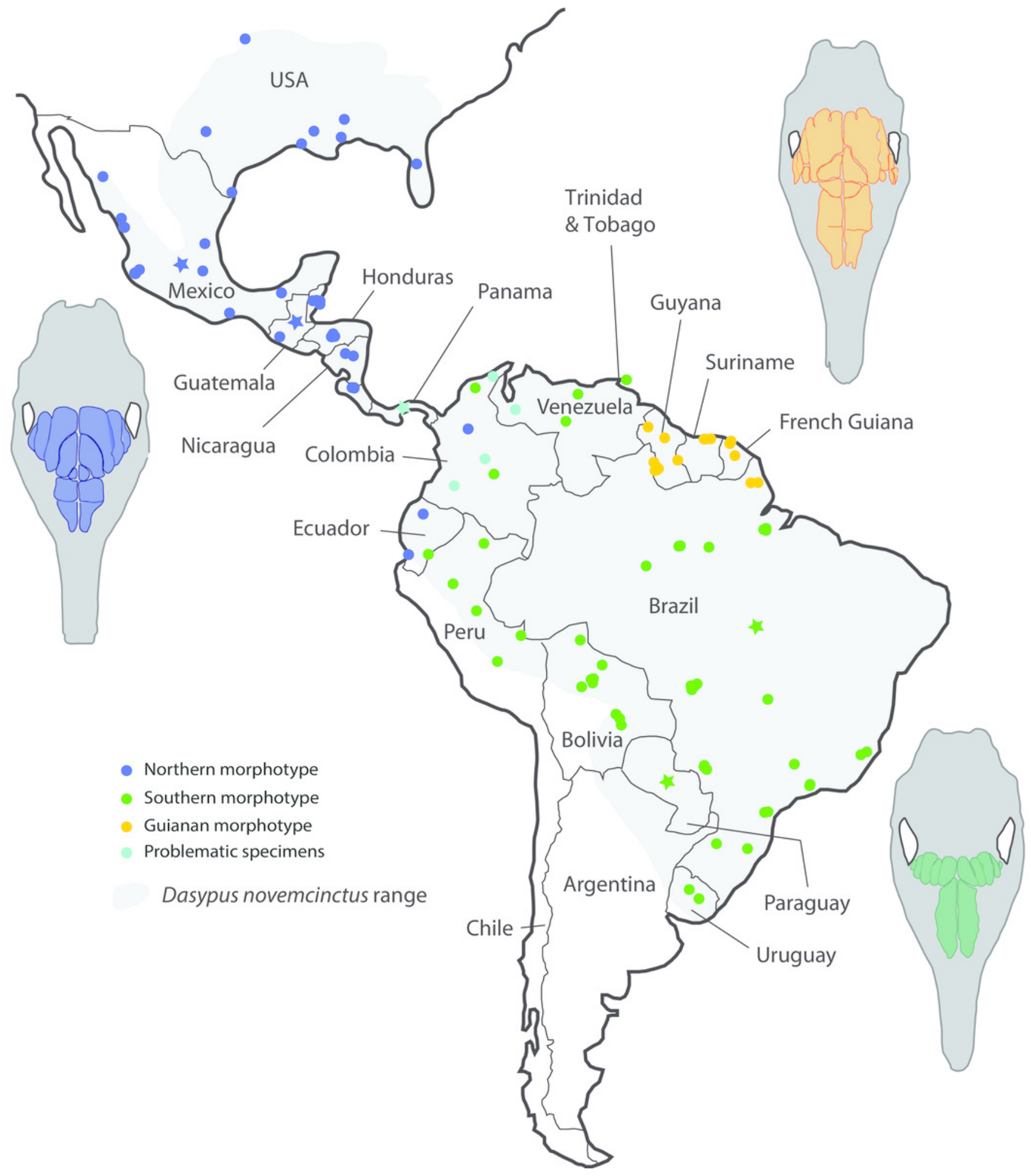

